Aus der Abteilung Medizinische Mikrobiologie

(Prof. Dr. med. U. Groß)

im Zentrum Hygiene und Humangenetik

der Medizinischen Fakultät

der Universität Göttingen

\title{
Optimierung der molekularbiologischen Diagnostik systemischer Mykosen
}

\author{
INAUGURAL-DISSERTATION \\ zur Erlangung des Doktorgrades
}

der Medizinischen Fakultät der

Georg-August-Universität zu Göttingen

vorgelegt von

Rolf Christian SCHETTLER

aus

Northeim

Göttingen 2012 
Dekan:

I. Berichterstatter:

II. Berichterstatter/in:

III. Berichterstatter/in:
Prof. Dr. med. C. Frömmel

Prof. Dr. med. U. Groß

Priv.-Doz. Dr. rer. nat. M. Weidmann

04.06 .2012 
I. Inhaltsverzeichnis I

II. Abkürzungsverzeichnis III

1. Einleitung 1

1.1. Bedeutung wichtiger Pilzarten als Krankheitserreger 1

1.2. Diagnostik von Pilzinfektionen 4

$\begin{array}{ll}\text { 1.3. Fragestellung und Motivation } & 6\end{array}$

$\begin{array}{lll}\text { 2. } & \text { Material und Methoden } & 7\end{array}$

$\begin{array}{lll}2.1 . & \text { Material }\end{array}$

2.1.1. Spezies 7

2.1.2. Geräte 8

2.1.3. Aufarbeitungssysteme/ PCR-Kits 9

2.1.4. Chemikalien 9

2.1.5. Primer/ Enzyme/ Sonden/ Antikörper 10

$\begin{array}{ll}\text { 2.1.6. Verbrauchsmaterialen } & 10\end{array}$

2.1.7. Lösungen 11

2.2. Methoden 12

2.2.1. Herstellung von seriellen Pilzverdünnungsreihen 12

2.2.2. Kultivierung der bakteriellen Negativkontrolle 13

2.2.3. Kultivierung und Aufarbeitung der PCR-Positivkontrolle 13

$\begin{array}{ll}\text { 2.2.4. DNA-Präparation aus seriellen Pilzverdünnungsreihen } 13 & 13\end{array}$

2.2.5. DNA-Präparation aus seriellen Pilzverdünnungsreihen in EDTA-Blut 19

2.2.6. DNA-Amplifikation via Polymerase-Kettenreaktion (PCR) 21

2.2.6.1. Primerdesign 23

2.2.6.2. PCR-Protokolle (A-C) 25

2.2.7. Agarose-Gelelektrophorese 30

2.2.8. Hybridisierung nach "Southern-Blot"-Verfahren 30

$\begin{array}{lll}\text { 2.2.8.1. Sonden } & 31\end{array}$

2.2.9. Kontaminationsprophylaxe/ Kontaminationsquellen 33

2.2.10. Standardisierung 33 
3. Ergebnisse

3.1. Vergleich der DNA-Präparationsprotokolle inkl.

Protokoll I. und II 34

3.1.1. Protokoll III. 35

$\begin{array}{lll}\text { 3.1.2. Protokoll IV. } & 37\end{array}$

3.1.3. Protokoll V. 38

3.1.4. Protokoll VI. 40

3.1.5. Protokoll VI.b. 41

3.1.6. Übersicht der Aufarbeitungsprotokolle 43

3.2. Vergleich der PCR-Amplifikationsprotokolle 43

3.2.1. PCR-Protokoll A / Standard 44

3.2.2. Southern-Blot 44

3.2.3 PCR-Protokoll B / Real-Time-PCR 46

3.2.4 PCR-Protokoll C / Nested-PCR 47

3.2.5 Übersicht der Amplifikationsprotokolle 49

4. Diskussion $\quad \mathbf{5 0}$

4.1. Effizienz der DNA-Extraktionen 51

4.2. Vergleich der DNA-Amplifikationsmethoden 54

$\begin{array}{lll}\text { 5. Zusammenfassung } & 58\end{array}$

$\begin{array}{ll}\text { 6. Literaturverzeichnis } & 59\end{array}$ 


\section{Abkürzungsverzeichnis}

ATCC

bp

Bsp.

bzw.

ca.

$\mathrm{cm}$

$\mathrm{cm}^{2}$

CFU

${ }^{\circ} \mathrm{C}$

$\mathrm{dd}_{2} \mathrm{O}$

d.h.

DNA

Dr.

DSMZ

E-cups

EDTA

et al.

$\mathrm{EtBr}$

evtl.

FRET

g

$\mathrm{h}$

$\mathrm{HCl}$

$\mathrm{H}_{2} \mathrm{O}$

HR-CT

inkl.

k.A.

$\mathrm{M}$

$\max$.

$\mathrm{mM}$
American Type Culture Collection

Basenpaare

Beispiel/ beispielsweise

beziehungsweise

circa

Zentimeter

Quadratzentimeter

Kolonie bildende Einheiten

Grad Celsius

doppelt destilliertes Wasser

das heißt

Desoxyribonukleinsäure

Doktor

Deutsche Sammlung für

Mikroorganismen und Zellkulturen

Eppendorf-cups

Ethylendiamintetraessigsäure

et alii ; und andere

Ethidiumbromid

eventuell

Fluoreszenz-Resonanz-Energie-Transfer

Gravitationskraft; Gramm

Stunde/n

Wasserstoffchlorid; Salzsäure

Wasser

hochauflösende Computertomografie

inklusive

keine Angabe

Mol

maximal

Milimol 
$\mathrm{mg}$

$\mathrm{Mg}^{2+}$

$\min$

mind.

$\mathrm{ml}$

$\mathrm{mm}$

$\mu l$

$\mathrm{N}_{2}$

ng

$\mathrm{nm}$

PBS

PCR

PD

pg

$\mathrm{pH}$

pmol

Prof.

RCLB

rpm

RT

RT-PCR

s.

s.Abb.

SDS

sek

spp.

Std.

Taq

$\mathrm{T}_{\mathrm{m}}$

$\mathrm{T}_{\mathrm{M}}$

Tris

Txp.a.

U
Milligramm

Magnesium

Minute

mindestens

Milliliter

Millimeter

Mikroliter

Stickstoff

Nanogramm

Nanometer

Phosphate-buffered-saline

Polymerasekettenreaktion

Privatdozent

Pikogramm

pondus Hydrogenii

Pikomol

Professor

Red-cell-lysis-buffer

rotation per minute/ Umdrehungen pro

Minute

Raumtemperatur

Real-Time-PCR/ Echtzeit-PCR

siehe

siehe Abbildung

Natriumdodecylsulfat

Sekunde/n

Spezies

Stunde

Thermophylus aquaticus

theoretischer Schmelzwert

DNA-Schmelzwert

Tris(hydroxymethyl)-aminomethan

Röntgen-Thorax-Aufnahme mit posterior-

anteriorem Strahlengang

Unit 


\section{u.a.}

Univ.

usw.

UV

vgl.

WCLB

Wiss.

$x$

z.B.

zzgl.

$\sim, \approx$

$\%$

$>$

$=$

\&

$-$

l

$\propto$

$\leq$

$\varnothing$

(

\section{Nukleotidbasen}

A

C

G

$T$

\section{Spezies}
A. flavus
A. fumigatus
C. albicans
C. glabrata
C. tropicalis
S. cerevisiae
S. aureus

unter anderem

Universität

und so weiter

Ultraviolett

vergleiche

White-cell-lysis-buffer

Wissenschaftlich/-e

$X$; mal

zum Beispiel

zuzüglich

ungefähr

Prozent

größer als

gleich

und

bis; minus; Bindestrich

pro; bei

unendlich

kleiner gleich

Durchmesser

geschütztes Markenzeichen

Purinbase Adenin

Pyrimidinbase Cytosin

Purinbase Guanin

Pyrimidinbase Thymidin

Aspergillus flavus

Aspergillus fumigatus

Candida albicans

Candida glabrata

Candida tropicalis

Saccharomyces cerevisiae

Staphylococcus aureus 


\section{Einleitung}

Pilze sind ubiquitär vorkommende eukaryontische Lebewesen, die bei einer Anzahl von 1.500.000 Spezies (Hawksworth, 2001) mehr als $1 / 4$ des Biomassenreservoirs der Erde ausmachen. Wurde im ausgehenden 18. Jahrhundert vom damaligen Direktor des Mannheimer Botanischen Gartens, F.C. Medicus (1803), noch die Auffassung proklamiert, dass Pilze spontan entstehen würden und nichts als Kristalle wären, die aus dem Schleim von verrottetem Material pflanzlichen und tierischen Ursprungs entstünden, so wissen wir heute, dass es sich durchaus um hochentwickelte Organismen handelt. Glücklicherweise sind hiervon nur ca. 150 Arten humanpathogen, bei denen die Hefe Candida albicans und der Schimmelpilz Aspergillus fumigatus aktuell eindeutig die häufigsten Erreger darstellen (Winston et al., 1995; Patel und Paya, 1997; Kullberg und Oude Lashof, 2002).

\subsection{Bedeutung wichtiger Pilzarten als Krankheitserreger}

Die meisten humanpathogenen Hefen und Schimmelpilze, so auch $C$. albicans und $A$. fumigatus, können als physiologische Haut- oder Schleimhautkommensalen auch bei Gesunden vorkommen und dann u.a. in Stuhlproben, Haut- und Schleimhautabstrichen nachgewiesen werden. Ohne Infektzeichen gilt dies jedoch „per definitionem" nicht als Infektion.

Innerhalb der vergangenen drei Dekaden hat die Inzidenz der invasiven Mykosen signifikant zugenommen (Wilson LS et al., 2002; Nucci und Marr, 2005; Bassetti et al., 2011). So hat sich beispielsweise die Anzahl der Candida - Infektionen in den USA vervielfacht, Candida rangiert als vierthäufigster Keim bei Blutinfektionen gleichauf mit gramnegativen Bakterien (Beck - Sagué und Jarvis, 1993; Abi-Said et al., 1997; Edmond et al., 1999; Wisplinghoff et al., 2004; Mikulska et al., 2011). Ähnliches gilt für Europa, wo Candida-Infektionen mit zu den am häufigsten nachgewiesenen Erkrankungen zählen (Bouza et al., 1999; Bouza und Munoz, 2008). Als Grund hierfür ist u.a. die zunehmende Anzahl immunkompromittierter Patienten mit HIV-Infektionen (Marty und Mylonakis, 2002) und deutlich ausgedehntere Intensivtherapieregime zu nennen. Verschiedene 
Pathogenitätsfaktoren sind in der Vergangenheit diesbezüglich diskutiert worden. Hierbei steht neben der Änderung des Wirtsmilieus und der damit verbundenen Verschiebung der mikrobiologischen Flora sowie einer evtl. vorliegenden Immundefizienz des Wirtsorganismus' in erster Linie die Adhäsion des Erregers an epitheliale Wirtszellen im Vordergrund, die als Anfang der Infektion nunmehr als Virulenzmechanismus akzeptiert ist (Sundstrom, 1999). Der weitere Krankheitsverlauf mit Übergang von Kolonisation und Invasion zur Disseminierung gestaltet sich oft fließend und ist klinisch nicht immer eindeutig. So kann sich z.B. C. albicans bei gastrointestinalen Infektionen als antibiotikaresistenter Keim in der gestörten Darmflora ungehinderter vermehren und leichter die Darmwand penetrieren (Andrutis et al., 2000).

Auch die Anzahl der Aspergillus - Infektionen steigt (Upton et al., 2007; Erjavec et al., 2009; Kriengkauykiat et al., 2011). Waren Anfang der neunziger Jahre noch rund $30 \%$ der Pilzinfektionen bei onkologischen Patienten auf Aspergillus zurückzuführen, so war dieser Schimmelpilz Anfang des neuen Jahrtausends schon Hauptinfektionsursache (Lin et al., 2001). Untersuchungen aus den USA ergaben, dass sich die Zahl der Aspergillus-assoziierten Todesfälle zwischen 1980 und 1997 vervierfacht hat (McNeil et al., 2001). Dies ist wahrscheinlich multifaktoriell bedingt, wobei die Hauptgründe u.a. in der Intensivierung chemotherapierter Tumorerkrankungen (Labbe et al., 2007) sowie ausgedehnterer Organtransplantationen (Rubin, 2002) mit iatrogener Immunsuppression zu sehen sind (Kousha et al., 2011). Auch eine potentere und oft zu schnell, zu lange und zu radikal durchgeführte Gabe von Breitbandantibiotika kann diesbezüglich begünstigend wirken.

Für C. albicans, 1846 erstmalig als Krankheitserreger beschrieben (Berg, 1846) und als Kommensale eigentlich harmlos, ist eine Einteilung zwischen nichtinvasiver und invasiver Candidose als Zustand der Infektion beschrieben (Bodey et al., 1993). Die nicht-invasive Candidose steht für die häufig milder verlaufende Form des Haut- und Schleimhautbefalls (z.B. mukokutane oder vulvovaginale Candidosen), sowie den Nachweis in verschiedenen Körperflüssigkeiten (z.B. urogenitaler Nachweis). Für die invasive Candidose lassen sich Subgruppen definieren: Die häufigste Form ist die Candidämie mit Nachweis von Candida spp. im Blut. Hiervon abgegrenzt werden kann die akut disseminierte Candidose mit hämatogen entstandener Organinvasion, sowie die chronisch disseminierte 
Candidose als manifeste Organinfektion. In neueren Studien hat sich gezeigt, dass neben Candida - Infektionen mit C. albicans zunehmend auch "Nicht albicans Stämme" eine Rolle spielen (Rangel-Frausto et al., 1999; Pfaller und Diekema, 2007; Hachem et al., 2008; Pereira et al., 2010; Mikulska et al., 2011). Hier seien vor allem C. tropicalis, C. glabrata und C. krusei (= Issatchenkia orientalis) genannt.

Die klinische Einteilung bei Aspergillus - Infektionen ist dagegen auf Grund von anfänglich oftmals fehlender Klinik schwieriger und wird häufig als „wahrscheinlich“ oder „nachgewiesen“ beschrieben.

Der in der Umwelt ubiquitär vorkommende Pilz, 1863 von Johann Baptist Georg Wolfgang Fresenius erstmals beschrieben (Fresenius, 1863), kann durch seine ungeschlechtlichen Sporen, den Konidien, vorzugsweise den Respirationstrakt, seltener den Gastrointestinaltrakt, das ZNS oder die Haut infizieren (Walsh, 1998). Diesbezüglich zeigen Untersuchungen auch die Möglichkeit der Übertragung durch kontaminiertes Leitungswasser (Warris et al., 2001). Neben A. fumigatus, der in $>80 \%$ der Fälle für eine humanpathogene Aspergillus-Infektion verantwortlich zu sein scheint, kommen mit abnehmender Relevanz auch $A$. flavus, A. terreus, A. niger und A. nidulans vor (Wald et al., 1997). Eine diagnostische Einteilung kann in eine akut- bzw. chronisch-invasive Aspergillose vorgenommen werden (Latgé, 1999). Die akute, meist pulmonal-invasive Aspergillose kann bei stark abwehrgeschwächtem Organismus disseminiert verlaufen, andere Organsysteme befallen und somit trotz eingeleiteter Therapie nicht selten letal enden (Denning, 1996; Patterson et al., 2000; Stevens et al., 2000; Wanke et al., 2000; Lin et al., 2001). Davon zu unterscheiden ist die chronisch-invasive Form des immunkompetenten Patienten mit lokalem Befall und Abkapselung (z.B. pulmonales Aspergillom). Auch sind nicht invasive Formen evident, z.B. die allergisch-bronchopulmonale Aspergillose, die bei Patienten mit allergischem Asthma als Hypersensitivitätsreaktion zu beobachten ist und zu keiner systemischen Infektion führt.

S. cerevisiae, eine auch als Bier- oder Bäckerhefe bekannte Gattung der Ascomyceten (= Schlauchpilze), hat unter Normalbedingungen keine pathologische Relevanz für den Menschen. Einige Stämme, so z.B. S. boulardii (= 
S. cerevisiae Hansen CBS 5926), werden gar als durchfallhemmende Mittel oder Appetitanreger therapeutisch eingesetzt.

\subsection{Diagnostik von Pilzinfektionen}

Bisher gestaltet sich die zeitgerechte Diagnostik der häufig immunsupprimierten, multimorbiden Patienten oft schwierig. So stellen Kliniker die Diagnose einer invasiven und nur all zu oft lebensbedrohlichen Pilzerkrankung nicht selten auf Grund „weicher“ klinischer Parameter: Verschlechterung des Allgemeinzustandes, Erhöhung der Infektionsparameter trotz antibiotischer Therapie, topische Keimbesiedlungen (z.B. Soor). Radiologische Untersuchungen (z.B. konventionelle Röntgen-Diagnostik bzw. HR-CT; s. Abb. 1, Bild 1 \& 2) können hier oft nur Verdachtsmomente widerspiegeln (Hjortrup et al., 1997).

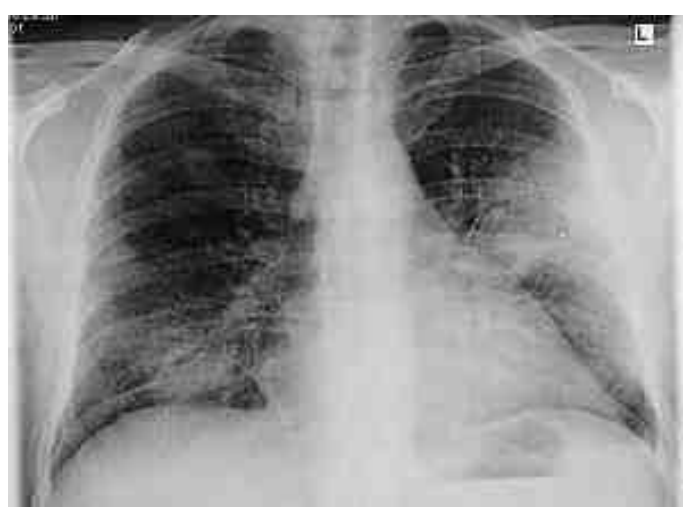

Bild 1: konventioneller Röntgen-Tx p.a.

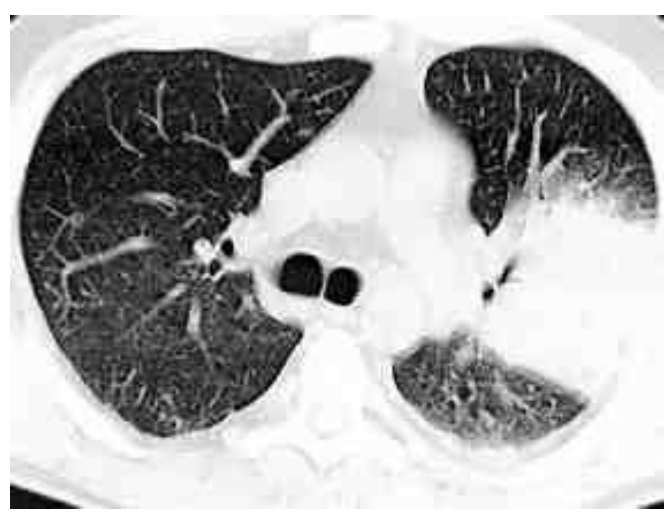

Bild 2: CT-Schichtaufnahme

Abbildung 1: 40-jähriger Patient mit Aspergillus-Pneumonie des linken Mittelfeldes bei maligner hämatologischer Grunderkrankung und iatrogener Immunsuppression

Ein zeitnaher Beginn der antimykotischen Therapie ist jedoch essenziell für eine gute Überlebensrate der Patienten (Morrell et al., 2005; Greene et al., 2007). Ist dies nicht gegeben, können leider auf Grund des oft raschen Progresses der Erkrankungen die meisten Pilz-Infektionen erst post mortem eindeutig diagnostiziert werden (Markin et al., 1990). Dies ist ein Grund, warum bei bisher fehlender Labor-Standardisierung der "Goldstandard“ zur klinischen Beurteilung 
invasiver Mykosen laut Empfehlung der DGHO (Deutsche Gesellschaft für Hämatologie/ Onkologie) weiterhin der kulturelle und/ oder der histopathologische Nachweis aus sonst sterilen Körperflüssigkeiten ist (Ruhnke et al., 2003). Diese diagnostischen Methoden sind jedoch sehr zeitaufwendig. Beispielsweise benötigt man für die kulturelle Anzüchtung und Differenzierung von $C$. albicans zwei bis drei Tage - bei $A$. fumigatus kann sich dies sogar noch weiter verzögern. Dadurch wird eine zeitnahe, valide Diagnose erschwert.

Bereits in den neunziger Jahren wurde deshalb intensiv nach Alternativmethoden für den Pilznachweis gesucht. Anfänglich gute Ergebnisse bei der Durchführung serologischer Detektionsverfahren begründeten bisher keinen Durchbruch als alleinige Nachweisverfahren (Ruhnke et al., 2003). So kann eine fehlende oder herabgesetzte Immunantwort bei Immunsuppression, z.B. im Rahmen onkologischer Therapieregime oder bei HIV-Infektionen, zu falsch negativen Testergebnissen führen. Auch kann die Verwertbarkeit von Antigentests an möglicher Kreuzreaktivität mit unspezifischen Antigenen (z.B. Rheumafaktoren) oder schlechter Sensibilität (Kappe et al., 1996) scheitern.

Mit dem Aufkommen der PCR-Methodik ab Mitte der achtziger Jahre wurden vermehrt molekularbiologische Verfahren für die mykologische Diagnostik eingesetzt. Im Laufe der Zeit haben sich daher viele Arbeitsgruppen mit unterschiedlichen DNA-Extraktionsverfahren beschäftigt (Müller et al., 1998; Löffler et al., 1997 \& 2000a; Bialek et al., 2001). Definiertes Ziel war und ist es, entweder durch mechanische Krafteinwirkung oder durch enzymatische Lyse PilzDNA standardisiert zu isolieren. In der nachfolgenden Amplifikation der DNA mittels PCR (Einsele et al., 1997; Löffler et al., 2000b; Jaeger et al., 2000) sollen dann möglichst niedrige Nachweisgrenzen erreicht werden. Die Spezifität für PilzDNA wird hierbei durch ein spezielles Design der Primersonden, die an sogenannte „18S-Multicopy-Gene“ des Pilzgenoms binden, gewährleistet. Da die Sonden „pilzspezifisch“, aber nicht „speziesspezifisch“ sind, ergibt sich so die Möglichkeit eines weitgefächerten „Screenings“ von Untersuchungsmaterial.

Zusammenfassend lässt sich sagen, dass mit Hilfe der modernen molekularbiologischen Verfahren ein Meilenstein in der Diagnostik invasiver Mykosen gesetzt wurde. Lediglich ein direkter Vergleich und eine einheitliche Standardisierung der unterschiedlichen Methoden stehen noch aus. 


\subsection{Fragestellung und Motivation}

Ziel der vorliegenden Arbeit war die Etablierung bzw. Identifikation einer möglichst sensitiven und spezifischen molekularbiologischen Methode zum Nachweis der häufigsten human-pathogenen Pilze $C$. albicans und $A$. fumigatus. Dabei sollte eine Standardisierung der Methodik bei möglichst geringem Zeitaufwand erreicht werden. Somit sollte ein Verfahren etabliert werden, das in die klinische Routinediagnostik integriert werden kann und valide Ergebnisse innerhalb von ein bis zwei Arbeitstagen ermöglicht.

Die Arbeit gliedert sich hierdurch in fünf wesentliche Teile:

- Der Vergleich von publizierten Aufarbeitungsprotokollen (s. 2.2.4., Protokolle I. - V.) unter standardisierten Labor- und PCR-Bedingungen

- Die Entwicklung eines optimierten und zusätzlichen „home-made“Protokolls (s. 2.2.4., Protokoll VI.)

- Die Untersuchung von artifiziell kontaminiertem EDTA-Blut (s. 2.2.5.)

- Der Vergleich unterschiedlicher, bekannter PCR-Methoden (s. 2.2.6.)

- Die Sensitivitätssteigerung durch „Southern-Blot“-Technik (s. 2.2.8.). 


\section{Material und Methoden}

\subsection{Material}

\subsubsection{Spezies}

Für die seriellen Verdünnungsreihen wurden die Pilzspezies freundlicherweise von Herrn Prof. Dr. Utz Reichard aus der Abteilung für Mykologie des Instituts für Medizinische Mikrobiologie der Universitätsmedizin Göttingen zur Verfügung gestellt. $C$. albicans und $S$. cerevisiae wurden dabei der „Deutschen Sammlung für Mikroorganismen und Zellkulturen" (DSMZ, Braunschweig) entnommen, bei $A$. fumigatus handelt es sich um ein Patientenisolat (Reichard et al., 1990):

Candida albicans

Saccharomyces cerevisiae

Aspergillus fumigatus
(DSMZ 6659)

(DSMZ 1333)

(D 141 / NRRL 6585).

Die mitgeführte bakterielle DNA wurde der „American Type of Culture Collection“ (ATCC, Rockville/ Maryland) entnommen und aus

Staphylococcus aureus

(ATCC; 25923)

isoliert.

Für die Erstellung der LightCycler®-Referenzkurven wurden zusätzlich folgende Pilz-Spezies mit einer Anzahl von $10^{6}$ Zellen / ml verwendet, die freundlicherweise von Frau Prof. Dr. M. Borg-von Zepelin aus dem Institut für Medizinische Mikrobiologie der Universitätsmedizin Göttingen zur Verfügung gestellt wurden: 
Candida albicans

Candida tropicalis

Candida tropicalis

Candida glabrata

Candida glabrata

Aspergillus flavus
[SC 5314] (klinisches Isolat nach Fonzi und Yrwin, 1993)

[DSMZ 4328]

[DSMZ 4959]

(klinisches Isolat der Mykologie Göttingen; Probe 1)

(klinisches Isolat der Mykologie Göttingen; Probe 2)

[DSMZ 818].

\subsubsection{Geräte}

\begin{tabular}{lll}
\hline Gerät & Modell & Hersteller \\
\hline Zentrifuge & $5415 \mathrm{C}$ & Eppendorf / Hamburg \\
Zentrifuge & $5417 \mathrm{R}$ & Eppendorf / Hamburg \\
Zentrifuge & $5415 \mathrm{D}$ & Eppendorf / Hamburg \\
Zentrifuge & Z233MK-2 & Hermle / Wehingen \\
Vortexer & Reax I & Heidolph / Schwabach \\
Thermomixer & Compact & Eppendorf / Hamburg \\
Thermomixer & Comfort & Eppendorf / Hamburg \\
Wasserbad & Typ 1012 & GFL / Burgwedel \\
Mikrowelle & KOR-63D7 & DAEWOO / Korea \\
Spannungsgerät & EPS 400 / 500 & Amersham / England \\
Elektrophoresekammer & & Stratagene/ USA \\
Waage & $440-33$ & Kern\&Sohn / Balingen \\
pH-Meter & 766 Calimatic & Knick / Berlin \\
pH-Meter & CG 804 & Schott / Hofheim \\
UV-Digitalkamera & Bio Doc II & Biometra / Göttingen \\
Thermocycler & T3 & Biometra / Göttingen \\
Zellruptierer & Fast Prep FP 120A-230 & Qbiogene / USA \\
Real-Time-PCR-Gerät & Light Cycler 1,5 & Roche / Mannheim \\
& &
\end{tabular}


Zählkammer

Durchlichtmikroskop

Aluminiumständer

(zum E-cup Verschluss)

Magnetrührer

Schwenktisch

Vakuumofen
THOMA-Zählkammer

Tiefe 0,1 mm; 0,0025 $\mathrm{mm}^{2}$

Axioskop 50

Monotherm

Duomax 1030

PVT 220
Carl Zeiss / Germany

Wiss. Werkstätten /

Univ. Göttingen

Supe-Rior / Germany

Variomag / USA

Heidolph / Schwabach

Heraeus / Hanau

\subsubsection{Aufarbeitungssysteme/ PCR-Kits}

System

Hersteller

Qiamp®DNA Mini-Kit

Qiagen GmbH / Hilden

FastDNA®Kit

Bio 101 / USA

LightCycler $\circledast$ FastStart DNA Master ${ }^{\text {Plus }}$

SYBR-Green I-Kit

Roche / Mannheim

\subsubsection{Chemikalien}

Bezeichnung

100 bp DNA Größenstandart

10x PCR Puffer

Magnesium-Chlorid

Ethidiumbromid

EDTA

SDS

Ethanol 96\%

Tris

Tris - $\mathrm{HCl} 99,9 \%$; $\mathrm{pH} 8,0 \quad \mathrm{C}_{4} \mathrm{H}_{11} \mathrm{NO}_{3}$

\section{Hersteller}

MBI Fermentas / St.

Leon-Rot

PCR Reaction Buffer

Roche / Mannheim

$\mathrm{MgCl}_{2} 25 \mathrm{mM}$

Roche / Mannheim

$\mathrm{C}_{21} \mathrm{H}_{20} \mathrm{BrN}_{3}$

Merck / Darmstadt

Ethylendiamintetra-

essigsäure

Roth / Karlsruhe

Natriumdodecylsulfat

$\mathrm{C}_{2} \mathrm{H}_{5} \mathrm{OH}$

Roth / Karlsruhe

Merck / Darmstadt

Tris(hydroxymethyl)-

Merck / Darmstadt

Aminomethan

Paesel \& Lorei /

Hanau 
Stickstoff (flüssig)

Natriumchlorid

Natriumhydrazidplätzchen

Salzsäure 37\% (rauchend)

$\beta$-Mercaptoethanol 99\%

Isopropanol (2-Propanol)

Phenol-Chloroform-Isoamyl-

Alkohol (25:24:1)

Agarose

Magermilchpulver

Detektionssystem

Tri-Na-Citratdihydrat
$\mathrm{NaCl}$

$\mathrm{NaOH}$

$\mathrm{HCl}$

$\mathrm{C}_{2} \mathrm{H}_{8} \mathrm{OS}$

$\mathrm{CH}_{3} \mathrm{CH}(\mathrm{OH}) \mathrm{CH}_{3}$

Roti Garose NEEO Ultra

Sucofin $\circledast$

ECL $®$-Detection-

Reagents (RPN 2105)

$\mathrm{C}_{6} \mathrm{H}_{5} \mathrm{O}_{7} \mathrm{Na}_{3}+2 \mathrm{H}_{2} \mathrm{O}$
Wiss. Werkstätten /

Univ. Göttingen

Roth / Karlsruhe

Merck / Darmstadt

Merck / Darmstadt

Roth / Karlsruhe

Merck / Darmtadt

Roth / Karlsruhe

Roth / Karlsruhe

Zeven / Germany

Amersham / England

Merck / Darmstadt

\subsubsection{Primer / Enzyme / Sonden / Antikörper}

\section{Bezeichnung}

Proteinase K-PCR Grade (20,6 mg / ml)

Proteinase $\mathrm{K}$

Primer \& Digoxigenin markierte Sonden

Anti-Digoxigenin Antikörper Fab fragments

(konjugiert mit Peroxidase; $150 \mathrm{mU} / \mathrm{ml}$ )

Zymolyase-100T (von Arthrobacter luteus)

(100.000 U/g)

Taq DNA Polymerase $(5 \mathrm{U} / \mu \mathrm{l})$

Heringssperma DNA

\section{Hersteller}

Roche / Mannheim

Qiagen / Hilden

Sigma / Steinheim

Roche / Mannheim

ICN Biomedicals /

USA

Roche / Mannheim

Invitrogen / USA

\subsubsection{Verbrauchsmaterialien}

\section{Bezeichung}

Pipettenspitzen mit Filter, steril

$(1000 \mu \mathrm{l}, 100 \mu \mathrm{l}, 10 \mu \mathrm{l})$

Impfschlingen, steril $(1 \mu \mathrm{l})$
Hersteller

Sarstedt / Nümbrecht

Sarstedt / Nümbrecht 
Safe-lock-cups $(1,5 \mathrm{ml})$

Eppendorf / Hamburg

Safe-seal micro-tube $(2 \mathrm{ml})$

Sarstedt / Nümbrecht

PCR Softtubes $(0,5 \mathrm{ml})$

Biozym Diagnostik /

Hess. Oldendorf

Nitrozellulose-Membran

Schleicher \& Schuell /

(Optitran BA-S 83; reinforced; 0,2 $\mu \mathrm{m}$ )

Dassel

Glasplatten und -wannen;

Wissenschftliche

Werkstätten /

Gelträger; Gelkämme

Univ. Göttingen

Gel Blotting-Papier (GB 004; 3 mm)

Schleicher \& Schuell /

Dassel

Glass-Beads $(0,5 \mathrm{~mm})$

Merlin / Holland

Agarplatten (Blut \& Sabouraud - Glucose)

Mikrobiologie /

Göttingen

Labor-Film Biomax ML

Eastman-Kodak / USA

\subsubsection{Lösungen}

Bezeichnung

Lysis buffer

TE-Puffer

White-cell-lysis-buffer (WCLB)

Zymolyase-Arbeitslösung

Red-cell-lysis-buffer (RCLB)

50x TAE-Puffer

Hydrolyselösung

Neutralisationslösung

Blockpuffer

Denhardt's Reagenz (50x)

\section{Zusammensetzung}

0,05M EDTA pH 8,0 + 0,3\% SDS

0,01M Tris- $\mathrm{HCl}$ - 0,001 M EDTA; $\mathrm{pH} 8,0$ $10 \mathrm{mM}$ Tris, $10 \mathrm{mM}$ EDTA, $50 \mathrm{mM} \mathrm{NaCl}$, 0,2 \% SDS, $200 \mu \mathrm{g}$ Proteinase $\mathrm{K} / \mathrm{ml}$ 300 mg Zymolase / ml, 50 mM Tris pH 7,5, 10mM EDTA, 28 mM $\beta$-Mercaptoethanol $10 \mathrm{mM}$ Tris $\mathrm{pH} 7,6,5 \mathrm{mM} \mathrm{MgCl} 2,10 \mathrm{mM}$ $\mathrm{NaCl}$

$2 \mathrm{M}$ Tris- $\mathrm{HCl}(\mathrm{pH} \mathrm{8,6)}, 50 \mathrm{mM}$ EDTA $(\mathrm{pH}$ 8,0), 5,7\% Essigsäure)

$1,5 \mathrm{M} \mathrm{NaCl}+0,5 \mathrm{M} \mathrm{NaOH}$

$1,5 \mathrm{M} \mathrm{NaCl}+0,5 \mathrm{M}$ Tris-Cl $\mathrm{pH} 8,0$

$1 \times$ PBS + 0,1\% Tween20 +

5\% Magermilchpulver $\mathrm{pH}$ 7,4

2\% Ficoll 400, 2\% Polyvinylpyrrolidon 
Prähybridisierungslösung

SSC

PBS (Phosphate-buffert-saline)
$1 \mathrm{M} \mathrm{Na}^{+}=10,8 \mathrm{ml} \mathrm{H} \mathrm{O}_{2} \mathrm{O}, 6 \mathrm{ml} 20 \times \mathrm{SSC}, 1$

$\mathrm{ml}$ SDS 10\%, 2 mg Denhardt's-Reagenz,

$0,2 \mathrm{mg}$ Heringssperma-DNA

$3 \mathrm{M} \mathrm{NaCl}+0,3 \mathrm{M}$ Natriumcitrat; $\mathrm{pH} 7,0$

$\mathrm{NaCl}+\mathrm{KCl}+\mathrm{Na}_{2} \mathrm{HPO}_{4}+\mathrm{KH}_{2} \mathrm{PO}_{4}$

\subsection{Methoden}

\subsubsection{Herstellung von seriellen Pilzverdünnungsreihen}

Die Zellen wurden einer 24 - 48 Stunden bei $37^{\circ} \mathrm{C}$ bebrüteten SabouraudGlucose-Agar-Platte entnommen, in PBS verdünnt und gleichmäßig gemischt. Danach wurde eine Thoma-Zählkammer mit $10 \mu \mathrm{l}$ der Suspension beschickt und die 16 Zählquadrate mit einem Durchlichtmikroskop mäanderförmig von links nach rechts ausgezählt. Die Berechnung der Zellzahl pro $\mathrm{ml}$ wurde nach folgender Formel durchgeführt:

\section{Zellzahl (Gesamt aller 16 Quadrate) / Quadrateanzahl $\times 2,5 \times 10^{5}=$ Zellen pro $\mathrm{ml}$}

Die Zellzahl wurde auf $1 \times 10^{6} / \mathrm{ml}$ mit PBS eingestellt und zu je $1000 \mu \mathrm{l}$ in $1,5 \mathrm{ml}$ Eppendorf-cups (E-cups) aliquotiert. Zur Kontrolle wurden abschließend nochmals $10 \mu$ l eines Aliquots in der Zählkammer ausgezählt.

Um standardisierte, serielle Verdünnungsreihen von $9 \times 10^{5}$ bis minimal $9 \times 10^{0}$

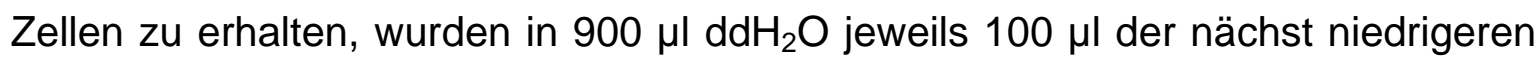
Verdünnungsstufe zugegeben und mindestens 5 sek gemischt (Bsp.: $100 \mu \mathrm{l}$ von

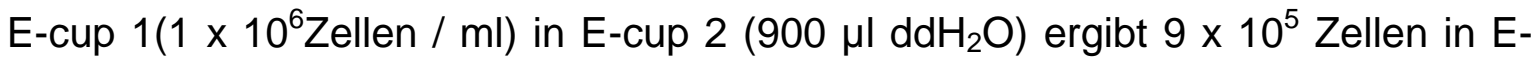
cup 1 und $1 \times 10^{5}$ Zellen in E-cup 2; usw.). 


\subsubsection{Kultivierung der bakteriellen Negativkontrolle}

Hierzu wurde eine Blutagar-Platte mittels "Drei-Ösen-Ausstrich" mit dem Bakterium S. aureus beimpft und bei $37^{\circ} \mathrm{C} 16$ Stunden bebrütet. Drei bis vier Bakterienkolonien wurden anschließend entnommen, mit $900 \mu \mathrm{ldd} \mathrm{H}_{2} \mathrm{O}$ verdünnt und in das DNA-Präparationsprotokoll integriert.

\subsubsection{Kultivierung und Aufarbeitung der PCR-Positivkontrolle}

Zur Bestätigung der einwandfreien Funktion der DNA-Amplifikationsmethoden wurde eine PCR-Positivkontrolle hergestellt.

Um die Dauer hierfür zu minimieren wurden von einer mit $C$. albicans beimpften Sabouraud-Glucose-Agarplatte vier bis fünf Kolonien abgenommen, mit $1,5 \mathrm{ml}$ $\mathrm{ddH}_{2} \mathrm{O}$ vermischt und zusammen mit ca. 200 - 300 mg "Glas-Beads“ ( $\left.\varnothing 0,5 \mathrm{~mm}\right)$ in ein "screw-cap"-Eppendorfgefäß überführt. Eingesetzt in den FastPrep®CellDisruptor wurde ein Zyklus von 3x 30 sek mit Geschwindigkeit 6.0 und 1x 40 sek mit ebenfalls 6.0 gewählt. Zwischen den Zyklen wurde die Probe jeweils auf Eis gekühlt. Danach folgte ein dreimaliger Zyklus von Kochen im Wasserbad bei $100^{\circ} \mathrm{C}$ für 5 min und Tieffrieren in flüssigem Stickstoff für $1 \mathrm{~min}$. Nach letztmaligem Aufkochen der Probe und folgender Abkühlung auf RT wurde die Aufarbeitung aliquotiert und für die PCR verwendet. Überschüssiges Material wurde für weitere Versuche bei $-20^{\circ} \mathrm{C}$ gelagert.

\subsubsection{DNA-Präparation aus seriellen Pilzverdünnungsreihen}

Insgesamt kamen sechs unterschiedliche DNA-Präparationsmethoden mit drei grundlegend unterschiedlichen Zelllysemechanismen zur Anwendung (Protokoll I. - VI.).

Zusätzlich zu den Verdünnungsreihen wurde bei jedem Aufarbeitungszyklus eine Bakterien- und eine Aufarbeitungsnegativkontrolle mitgeführt.

Protokoll I. $\Rightarrow \quad$ mechanische Ruptur mit Bio101 Fast DNA@Kit

1.) Herstellung der seriellen Verdünnungsreihen mit $9 \times 10^{5}-9 \times 10^{0}$ Zellen

2.) Zentrifugation mit $14.000 \times \mathrm{g} / 10 \mathrm{~min}$; Überstände verwerfen

3.) Resuspendieren der Pellets in $100 \mu \mathrm{lddH} \mathrm{d}_{2} \mathrm{O}$ 
4.) Überführen der Proben in Bio 101-cup; Mischung mit $1000 \mu \mathrm{l} \mathrm{CLS-Y} \mathrm{Puffer}$ (Beads)

5.) Einsetzen in Fast Prep ${ }^{\circledR C}$ Cell-Disruptor; Zellzertrümmerung für $2 \times 20$ sek mit eingestellter Geschwindigkeit 5.0

6.) Zentrifugation $14.000 \times \mathrm{g} / 5 \mathrm{~min}$

7.) Überstände in neue E-cups überführen und weitere 5 min bei $14.000 \times g$ zentrifugieren

8.) $600 \mu \mathrm{l}$ der Überstände in neue E-cups überführen und mit $600 \mu \mathrm{l}$ „bindingmatrix" bis zur Homogenität mischen

9.) Inkubation von $5 \mathrm{~min}$ bei RT

10.) Zentrifugation $14.000 \times \mathrm{g} / 1 \mathrm{~min}$

11.) Verwerfen der Überstände und Resuspension der Pellets mit $500 \mu \mathrm{I}$ SEWSM Puffer

12.) Zentrifugation $14.000 \times \mathrm{g} / 1 \mathrm{~min}$

13.) Verwerfen der Überstände und weitere Zentrifugation bei $14.000 \times \mathrm{g} / 10$ sek

14.) Elution der DNA durch Zugabe von $100 \mu$ I DES Puffer

15.) Inkubation 2-3 min

16.) Zentrifugation $14.000 \times \mathrm{g} / 1 \mathrm{~min}$

17.) Überführung der Überstände in neue E-cups und Ansetzen der PCRReaktionen

Dauer: ca. 4 Std.

Protokoll II. $\Rightarrow \quad$ mechanische Ruptur mittels „Glass-Beads“ in Fast Prep @CellDisruptor (modifiziert nach Müller et al., 1998)

1.) Herstellung der seriellen Verdünnungsreihen mit $9 \times 10^{5}-9 \times 10^{0}$ Zellen

2.) Zentrifugation $14.000 \times \mathrm{g} / 10 \mathrm{~min}$; Überstände verwerfen

3.) Inkubation der Pellets in $500 \mu \mathrm{l}$ "Lysis buffer" (0,05M EDTA pH 8,0 + 0,3\% SDS) für $45 \mathrm{~min}$ bei $\mathrm{RT}$

4.) Überführen der Proben in 2-ml-screw-cap-Eppendorf-Gefäße und Auffüllen mit ca. 200-300 mg „Glass-Beads“ ( $\varnothing$ 0,5mm) 
5.) Zertrümmerung der Zellen für 30 sek bei Geschwindigkeit 6.5

6.) Kühlen der Gefäße auf Eis für $10 \mathrm{~min}$

7.) Wiederholung von Punkt 5.) und 6.)

8.) Zentrifugation $14.000 \times \mathrm{g} / 5 \mathrm{~min}$

9.) Abnehmen der Überstände und Überführung in neue E-cups

10.) Zugabe von $300 \mu \mathrm{l}$ „glass-milk-binding-matrix“ (aus Bio101 FastDNA®Kit)

11.) Mischung per Inversion für 2-3 min

12.) Zentrifugation $14.000 \times \mathrm{g} / 3 \mathrm{~min}$

13.) Verwerfen der Überstände

14.) Resuspension der Pellets in $500 \mu \mathrm{l} 80 \%$ Ethanol

15.) Zentrifugation $14.000 \times \mathrm{g} / 2 \mathrm{~min}$

16.) Verwerfen der Überstände

17.) Wiederholung von Punkt 15.) und 16.)

18.) Resuspension der Pellets in $100 \mu$ TE-Puffer $(\mathrm{pH} 8,0)$

19.) Kochen im Wasserbad bei $70^{\circ} \mathrm{C} / 10 \mathrm{~min}$

20.) Zentrifugation $14.000 \times \mathrm{g} / 2 \mathrm{~min}$

21.) Überführen der Überstände in neue E-cups und Ansetzen der PCRReaktionen

Dauer: ca. 4 Std.

Protokoll III. $\Rightarrow \quad$ enzymatisch-thermische Lyse mit Phenol-ChloroformExtraktion (nach Löffler et al., 2000a)

1.) Herstellung der seriellen Verdünnungsreihen mit $9 \times 10^{5}-9 \times 10^{0}$ Zellen

2.) Auffüllen der E-cups mit $\mathrm{dd}_{2} \mathrm{O}$ auf je $1000 \mu \mathrm{l}$ Geamtvolumen

3.) Zentrifugation $12.700 \mathrm{xg} / 10 \mathrm{~min}$

4.) Verwerfen von $900 \mu \mathrm{l}$

5.) Zugabe von $500 \mu$ WCLB-Puffer; Inkubation $45 \mathrm{~min} / 65^{\circ} \mathrm{C}$ bei $1400 \mathrm{rpm}$

6.) 3-maliger Zyklus: 1 min schockgefrieren in Stickstoff 5 min kochen im Thermoblock bei $95^{\circ} \mathrm{C} / 800 \mathrm{rpm}$

7.) Abkühlen auf RT / Anzentrifugation / Überführung in 2-ml-E-cups 
8.) Zugabe von $500 \mu \mathrm{ldd} \mathrm{H}_{2} \mathrm{O}$ und $500 \mu \mathrm{l}$ Phenol-Chlororform-Isoamylalkohol (25:24:1); gründlich vortexen

9.) Überführung der oberen Phase in neue E-cups

10.) Zugabe von $900 \mu \mathrm{l}$ Isopropanol (eiskalt; Lagerung bei $-20^{\circ} \mathrm{C}$ ); entspricht einem Verhältnis 1:1 zum Probenmaterial

11.) gründliches Vortexen und Lagerung bei $-80^{\circ} \mathrm{C} / 10 \mathrm{~min}$

12.) Zentrifugation $15.000 \times \mathrm{g} / 10 \mathrm{~min}$ bei $4^{\circ} \mathrm{C} /$ Verwerfen der Überstände

13.) Zugabe von $500 \mu \mathrm{l} \mathrm{EtOH} 70 \%$; nicht vortexen!

14.) Zentrifugation mit $14.000 \times \mathrm{g} / 5 \mathrm{~min}$; Überstände verwerfen

15.) Trocknung der Pellets in geöffneten E-cups im Thermoblock bei $37^{\circ} \mathrm{C}$

16.) Zugabe von $100 \mu \mathrm{ldd} \mathrm{H}_{2} \mathrm{O}$, Vortexen und Ansetzen der PCR-Reaktionen

Dauer: ca. 4 Std.

Protokoll IV. $\Rightarrow \quad$ thermische Ruptur mit Qiagen-Präparation

(nach Bialek et al., 2001)

1.) Herstellung der seriellen Verdünnungsreihen mit $9 \times 10^{5}-9 \times 10^{0}$ Zellen

2.) Zentrifugation der E-cups für $12.700 \times$ g; Überstände verwerfen

3.) Zugabe von $180 \mu \mathrm{l}$ ATL-Puffer und $20 \mu \mathrm{l}$ Proteinase K (jeweils aus dem Qiamp $\circledast D N A$ Mini-Kit); vortexen für ca. 5 sek

4.) Inkubation mind. $2 \mathrm{Std}$. bei $55^{\circ} \mathrm{C} / 1100 \mathrm{rpm}$ im Thermoblock

5.) Einsetzen der E-cups in Aluminium-Ständer mit zusätzlichem mechanischen Verschluss der E-cup-Deckel

6.) Kochen im Wasserbad bei $100^{\circ} \mathrm{C}$ für 5 min

7.) 3-maliger Zyklus: 1 min schockgefrieren in Stickstoff 5 min kochen im Wasserbad

8.) Abkühlung auf RT

9.) Zugabe von $20 \mu \mathrm{l}$ Proteinase $\mathrm{K}$; vortexen für ca. 5 sek

10.) Inkubation für $1 \mathrm{Std}$. im Thermoblock bei $55^{\circ} \mathrm{C} / 1100 \mathrm{rpm}$

11.) Anzentrifugieren der E-cups und Zugabe von $200 \mu \mathrm{l}$ AL-Puffer

12.) $15 \mathrm{sec}$ vortexen und $10 \mathrm{~min}$ bei $70^{\circ} \mathrm{C}$ im Thermoblock (1100 rpm) inkubieren; anzentrifugieren 
13.) Zugabe von $200 \mu$ Ethanol (99\%); 15 sek vortexen; anzentrifugieren

14.) Überführung der Suspensionen in Qiagen-Säulen; Zentrifugation $1 \mathrm{~min} /$ $6000 \times \mathrm{g}$

15.) Überführung der Säulen in neue 2-ml-Gefäße

16.) Zugabe von $500 \mu \mathrm{l}$ AW1-Puffer; Zentrifugation $6000 \mathrm{x} \mathrm{g} / 1 \mathrm{~min}$

17.) Überführung der Säulen in neue 2-ml-Gefäße

18.) Zugabe von $500 \mu \mathrm{l}$ AW2-Puffer; Zentrifugation $1000 \mathrm{xg} / 3 \mathrm{~min}$

19.) Überführung der Säulen in 1,5-ml-E-cups

20.) Elution durch Zugabe von $100 \mu \mathrm{AE}$-Puffer; Inkubation 1 min bei RT; Zentrifugation $6000 \mathrm{xg} / 1 \mathrm{~min}$

21.) Ansetzen der PCR-Reaktionen

Dauer: ca. 5 Std.

Protokoll V. $\Rightarrow \quad$ enzymatische Lyse mit Qiagen-Präparation (nach Löffler et al., 1997)

1.) Herstellung der seriellen Verdünnungsreihen mit $9 \times 10^{5}-9 \times 10^{0}$ Zellen

2.) Zentrifugation $12.700 \times \mathrm{g} / 10 \mathrm{~min}$; Überstände verwerfen

3.) Pellets in $1 \mathrm{ml}$ WCLB aufnehmen und für mind. 45 min (max. 2 Std.) bei $65^{\circ} \mathrm{C} / 1400 \mathrm{rpm}$ im Thermoblock inkubieren

4.) Zentrifugation $2000 \times \mathrm{g} / 10 \mathrm{~min}$; Überstände verwerfen

5.) Pellets in $500 \mu \mathrm{l} 50 \mathrm{mM} \mathrm{NaOH}$ aufnehmen; Inkubation im Thermoblock bei $95^{\circ} \mathrm{C} / 10 \mathrm{~min}$

6.) Neutralisation mit $25 \mu \mathrm{l} 1 \mathrm{M} \mathrm{HCl}$; Zentrifugation $2500 \mathrm{x} \mathrm{g} / 10 \mathrm{~min}$; Überstände verwerfen

7.) Inkubation der Pellets mit $500 \mu \mathrm{l} Z$ ymolyase-Arbeitslösung für $45 \mathrm{~min} / 37^{\circ} \mathrm{C}$ im Thermoblock

8.) Zentrifugation $5000 \mathrm{xg} / 10 \mathrm{~min}$; Überstände verwerfen

9.) Zugabe von $180 \mu \mathrm{l}$ ATL-Puffer $+20 \mu \mathrm{l}$ Proteinase-K (jeweils aus dem Qiamp®DNA Mini-Kit) und Inkubation bei $56^{\circ} \mathrm{C} / 1100$ rpm im Thermoblock mind. 2 Std.

10.) E-cups anzentrifugieren

11.) Zugabe von $200 \mu \mathrm{l}$ AL Puffer 
12.) 15 sek vortexen und $10 \mathrm{~min}$ bei $70^{\circ} \mathrm{C}$ im Thermoblock (1100 rpm) inkubieren; anzentrifugieren

13.) Zugabe von $200 \mu \mathrm{l}$ Ethanol (99\%); 15 sek vortexen; anzentrifugieren

14.) Überführung der Suspensionen in Qiagen-Säulen; Zentrifugation $1 \mathrm{~min} /$ $6000 \times \mathrm{g}$

15.) Überführung der Säulen in neue 2-ml-Gefäße

16.) Zugabe von $500 \mu \mathrm{l}$ AW1-Puffer; Zentrifugation $6000 \mathrm{x} \mathrm{g} / 1 \mathrm{~min}$

17.) Überführung der Säulen in neue 2-ml-Gefäße

18.) Zugabe von $500 \mu \mathrm{l}$ AW2-Puffer; Zentrifugation $1000 \mathrm{xg} / 3 \mathrm{~min}$

19.) Überführung der Säulen in 1,5-ml-E-cups

20.) Elution durch Zugabe von $100 \mu \mathrm{l}$ AE-Puffer; Inkubation 1 min bei RT; Zentrifugation $6000 \mathrm{xg} / 1 \mathrm{~min}$

21.) Ansetzen der PCR-Reaktionen

Dauer: ca. $61 / 2$ Std.

Protokoll VI. $\Rightarrow \quad$ enzymatische Lyse mit thermischer Ruptur und QiagenPräparation (Lugert et al., 2006)

1.) Herstellung der seriellen Verdünnungsreihen mit $9 \times 10^{5}-9 \times 10^{0}$ Zellen

2.) Zentrifugation $12.700 \times \mathrm{g} / 10 \mathrm{~min}$; Überstände verwerfen

3.) Pellets in $1 \mathrm{ml}$ WCLB aufnehmen und für mind. 45 min (max. 2 Std.) bei $65^{\circ} \mathrm{C} / 1400 \mathrm{rpm}$ im Thermoblock inkubieren

4.) Zentrifugation $2000 \mathrm{x} \mathrm{g} \mathrm{/} 10 \mathrm{~min}$; Überstände verwerfen

5.) Inkubation der Pellets mit $500 \mu \mathrm{l}$ Zymolyase-Arbeitslösung für $45 \mathrm{~min} / 37^{\circ} \mathrm{C}$ im Thermoblock

6.) Zentrifugation $5000 \mathrm{xg} / 10 \mathrm{~min}$; Überstände verwerfen

7.) Zugabe von $180 \mu \mathrm{l}$ ATL-Puffer $+20 \mu \mathrm{l}$ Proteinase-K (jeweils aus dem Qiamp®DNA Mini-Kit) und Inkubation bei $55^{\circ} \mathrm{C} / 1100 \mathrm{rpm}$ im Thermoblock mind. 2 Std.

8.) Einsetzen der E-cups in Aluminium-Ständer mit zusätzlichem mechanischen Verschluss der E-cup-Deckel

9.) Kochen im Wasserbad bei $100^{\circ} \mathrm{C}$ für $5 \mathrm{~min}$ 
10.) 3-maliger Zyklus: 1 min schockgefrieren in Stickstoff 5 min kochen im Wasserbad

11.) Abkühlung auf $R T$

12.) E-cups anzentrifugieren

13.) Zugabe von $200 \mu \mathrm{l}$ AL Puffer

14.) 15 sek vortexen und $10 \mathrm{~min}$ bei $70^{\circ} \mathrm{C}$ im Thermoblock (1100 rpm) inkubieren; anzentrifugieren

15.) Zugabe von $200 \mu$ l Ethanol (99\%); 15 sek vortexen; anzentrifugieren

16.) Überführung der Suspensionen in Qiagen-Säulen; Zentrifugation $1 \mathrm{~min} /$ $6000 \times g$

17.) Überführung der Säulen in neue 2-ml-Gefäße

18.) Zugabe von $500 \mu \mathrm{l}$ AW1-Puffer; Zentrifugation $6000 \mathrm{x} \mathrm{g} / 1 \mathrm{~min}$

19.) Überführung der Säulen in neue 2-ml-Gefäße

20.) Zugabe von $500 \mu \mathrm{l}$ AW2-Puffer; Zentrifugation $1000 \mathrm{x} \mathrm{g} / 3 \mathrm{~min}$

21.) Überführung der Säulen in 1,5-ml-E-cups

22.) Elution durch Zugabe von $100 \mu \mathrm{l}$ AE-Puffer; Inkubation 1 min bei RT; Zentrifugation $6000 \mathrm{xg} / 1 \mathrm{~min}$

23.) Ansetzen der PCR-Reaktionen

Dauer: ca. 8 Std.

\subsubsection{DNA-Präparation aus seriellen Pilzverdünnungsreihen in EDTA-Blut}

Die seriellen Pilzverdünnungsreihen (s. 2.2.1) wurden mit $100 \mu$ l humanem EDTABlut einer gesunden Spenderin gemischt und mit der sensitivsten DNAPräparationsmethode (Protokoll VI., s. 2.2.4.) unter vorheriger hypotoner Erythrozytenlyse aufgearbeitet. Somit kann die Sensitivität zwischen PBS- und blutversetzten Pilzsuspensionen verglichen werden. 
Protokoll VI.b. $\Rightarrow$ hypotone, enzymatische Lyse mit thermischer Ruptur und Qiagen-Präparation (Lugert et al., 2006)

1.) Herstellung der seriellen Verdünnungsreihen mit $9 \times 10^{5}-9 \times 10^{0}$ Zellen

2.) Zentrifugation $12.700 \times \mathrm{g} / 10 \mathrm{~min}$; Überstände verwerfen

3.) Pellets in $100 \mu \mathrm{l}$ EDTA-Blut aufnehmen; vortexen

4.) Erythrozyten-Lyse durch Zugabe von $800 \mu \mathrm{l}$ RCLB

5.) Inkubation bei $\mathrm{RT}\left(25^{\circ} \mathrm{C}\right) / 10 \mathrm{~min}$ im Thermoblock ( $\left.1400 \mathrm{rpm}\right)$

6.) Zentrifugation $5000 \mathrm{xg} / 10 \mathrm{~min}$; Überstände verwerfen

7.) Pellets in $1 \mathrm{ml}$ WCLB aufnehmen und für mind. 45 min (max. 2 Std.) bei $65^{\circ} \mathrm{C} / 1400 \mathrm{rpm}$ im Thermoblock inkubieren

8.) Zentrifugation $2000 \mathrm{xg} / 10 \mathrm{~min}$; Überstände verwerfen

9.) Inkubation der Pellets mit $500 \mu \mathrm{l} Z$ zymolyase-Arbeitslösung für $45 \mathrm{~min} / 37^{\circ} \mathrm{C}$ im Thermoblock

10.) Zentrifugation $5000 \mathrm{xg} / 10 \mathrm{~min}$; Überstände verwerfen

11.) Zugabe von $180 \mu \mathrm{l}$ ATL-Puffer $+20 \mu \mathrm{l}$ Proteinase-K (jeweils aus dem Qiamp®DNA Mini-Kit) und Inkubation bei $55^{\circ} \mathrm{C} / 1100 \mathrm{rpm}$ im Thermoblock mind. 2 Std.

12.) Einsetzen der E-cups in Aluminium-Ständer mit zusätzlichem mechanischen Verschluss der E-cup-Deckel

13.) Kochen im Wasserbad bei $100^{\circ} \mathrm{C}$ für $5 \mathrm{~min}$

14.) 3-maliger Zyklus: 1 min schockgefrieren in Stickstoff 5 min kochen im Wasserbad

15.) Abkühlung auf $R T$

16.) E-cups anzentrifugieren

17.) Zugabe von $200 \mu \mathrm{l}$ AL Puffer

18.) 15 sek vortexen und $10 \mathrm{~min}$ bei $70^{\circ} \mathrm{C}$ im Thermoblock (1100 rpm) inkubieren; anzentrifugieren

19.) Zugabe von $200 \mu \mathrm{l}$ Ethanol (99\%); 15 sek vortexen; anzentrifugieren

20.) Überführung der Suspensionen in Qiagen-Säulen; Zentrifugation $1 \mathrm{~min} /$ $6000 \times \mathrm{g}$

21.) Überführung der Säulen in neue 2-ml-Gefäße

22.) Zugabe von $500 \mu \mathrm{l}$ AW1-Puffer; Zentrifugation $6000 \mathrm{x} \mathrm{g} / 1 \mathrm{~min}$

23.) Überführung der Säulen in neue 2-ml-Gefäße 
24.) Zugabe von $500 \mu$ l AW2-Puffer; Zentrifugation $1.000 \times$ g / 3 min

25.) Überführung der Säulen in 1,5-ml-E-cups

26.) Elution durch Zugabe von $100 \mu \mathrm{l}$ AE-Puffer; Inkubation 1 min bei RT; Zentrifugation $6000 \times \mathrm{g} / 1 \mathrm{~min}$

27.) Ansetzen der PCR-Reaktionen

Dauer: ca. 8,5 Std.

\subsubsection{DNA-Amplifikation via Polymerase-Kettenreaktion (PCR)}

Die PCR ist eine in-vitro-Methode zur Amplifikation definierter DNA-Sequenzen (Mullis et al., 1986).

Das Enzym ist die Taq-Polymerase, eine thermostabile DNA-Polymerase. Die Reaktion kann in drei unterschiedliche Teilbereiche untergliedert werden:

a.) Denaturierung und damit Aufspaltung der DNA-Stränge

b.) Anlagerung („Annealing“) der sequenzspezifischen Oligonukleotide („Primer“) an die komplementäre DNA-Sequenz

c.) Amplifikation der DNA durch Synthese neuer „Tocher“-DNA-Stränge.

Dieser Zyklus wird mehrfach wiederholt, wodurch eine ausreichende Menge an DNA generiert wird.

Da die Aufheiz- und Abkühlzeiten in konventionellen Thermocyclern (s. 2.2.6.2., Protokoll A) bauartbedingt vordefiniert sind, wurde zur weiteren Zeitoptimierung des Untersuchungsablaufs ein Real-Time-PCR-Protokoll (s. 2.2.6.2., Protokoll B) unter Verwendung des Light-Cycler $\AA-1.5-S y s t e m s$ von Roche $₫$ mitverglichen.

Der Light-Cycler ${ }^{\circledR}$ der Firma Roche ${ }^{\circledR}$ ist ein Thermocycler mit optischer Einheit (Wittwer et al., 1990; Wittwer und Garling, 1991). Wie im konventionellen Thermoblock wird auch hier die Temperatur während des PCR-Zyklus im Thermocycler reguliert. Dies geschieht allerdings nicht durch Erhitzen einer statischen Masse, sondern durch Luftzirkulation mittels Ventilatortechnik, die, je nach Messprogramm, durch eine Heizspindel entsprechend reguliert werden kann. 
Durch die relativ geringe Wärmekapazität der Luft ist es somit möglich, schnelle Temperaturgradienten von bis $z u 20^{\circ} \mathrm{C}$ pro Sekunde mit einer Abweichung von $\pm 0,3^{\circ} \mathrm{C}$ am Probenmaterial zu generieren. Das Probenkarussell, bestehend aus

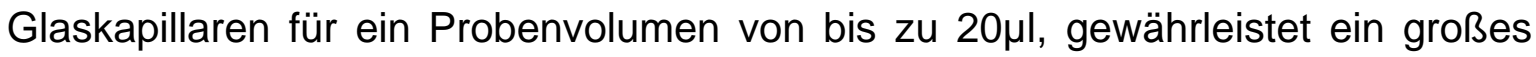
Verhältnis von Oberfläche zu untersuchtem Material und begünstigt somit ebenfalls eine kurze Amplifikationsdauer durch schnelle Aufheiz- und Abkühlzyklen. In der implantierten optischen Einheit wird über Photodioden die emittierte Fluoreszenz des generierten PCR-Produktes gemessen. Hierdurch kann die DNA-Amplifikation in Echtzeit („Real-Time“) am Monitor durch die entsprechende Software grafisch dargestellt werden, da der Anstieg der Fluoreszenz mit jedem neuen PCR-Zyklus in direktem Verhältnis zum generierten PCR-Produkt steht. Dies kann in Bezug zur Zyklenzahl visualisiert werden. Abhängig von der eingesetzten Menge der Ziel-DNA heben sich nach einer bestimmten Zyklenzahl die emittierten Fluoreszenzsignale des generierten PCRProdukts signifikant von denen des Hintergrundes ab (Phase der exponentiellen Signalzunahme). Dieser Punkt wird von der Software erkannt und ist als Crossing Point definiert, d.h. als der Punkt, an dem der exponentielle und damit quantifizierbare Anstieg der DNA-Menge stattfindet. Über die Bestimmung der Crossing Points können daher quantitative Aussagen über die Ausgangsmenge an Ziel-DNA getätigt werden. Bei Messzeiten von 20 Millisekunden pro Kapillare lässt sich somit eine komplette PCR unterhalb einer Stunde realisieren (Wittwer et al., 1997a; Rasmussen, 2001).

In der vorliegenden Arbeit wurde für die Real-Time-PCR-Untersuchungen das „LightCycler FastStart DNA Master ${ }^{\text {Plus }}$ SYBR Green I - Kit“ nach Herstellerangaben verwendet, um neben $C$. albicans und $A$. fumigatus auch die apathogene Spezies $S$. cerevisiae detektieren zu können und somit ein breites Screeningspektrum zu gewährleisten.

Die Amplifikation der DNA wird dabei durch Messung des vom sequenzunabhängigen Cyaninfarbstoffes SYBR-Green ausgehenden fluoreszierenden Signals bei $530 \mathrm{~nm}$ gemessen. Dieses Signal wird bei Bindung von SYBR-Green in die Doppelstrang-DNA emittiert und nimmt proportional mit der amplifizierten DNA-Menge zu. Die enthaltene FastStart Taq Polymerase basiert auf der "Hot-Start"-Technologie und minimiert somit die Amplifikation von unspezifischen PCR-Produkten (Kellogg et al., 1994; Birch, 1996). 
Ein Nachteil hierbei ist jedoch die geringe Spezifität, da zwischen den unterschiedlichen PCR-Produkten während der Amplifikation nicht direkt unterschieden werden kann. Dies lässt sich ausgleichen, indem nach abgelaufener PCR eine Schmelzkurvenanalyse durchgeführt wird, wodurch auf Grund unterschiedlicher Schmelzpunkte der gebildeten PCR-Amplifikate eine Spezifizierung vorgenommen werden kann. Hierbei wird die DNA durch kontinuierliche Temperaturerhöhung auf bis $z u 5^{\circ} \mathrm{C}$ aufgeschmolzen. Bei einem für das DNA-Fragment spezifischen Temperaturwert denaturiert der DNADoppelstrang zu zwei Einzelsträngen. Dadurch wird der Farbstoff SYBR-Green freigesetzt. Nachfolgend erfolgt eine Fluoreszenzabnahme, so dass ein grafisch darstellbarer Peak entsteht. Da die DNA von spezifischen PCR-Produkten einen höheren Schmelzpunkt hat als unspezifische Primerdimere, ist eine Unterscheidung möglich. Die Höhe des Peaks kann hierbei eine näherungsweise Aussage über die synthetisierte DNA-Menge geben.

\subsubsection{Primerdesign}

Es wurden drei unterschiedliche PCR-Protokolle (s. 2.2.6.2., Protokoll A - C) zur Amplifikation genutzt. Bei den Protokollen A und $C$ wurden die PCR-Analysen stets im selben Thermocycler (T3; Biometra/ Göttingen) unter identischen Bedingungen durchgeführt. Protokoll B (abgewandelt nach Löffler et al., 2000b) verwendet das Real-Time PCR-System („Light-Cycler ${ }^{\circ} 1,5^{\prime \prime}$ ) von Roche.

Das PCR-Produkt wurde anschließend mittels Flachbett-Gelelektrophorese (s. 2.2.7.) dargestellt.

\section{Primerdesign der Protokolle $A$ \& B}

Um möglichst alle Pilzspezies zu erfassen, wurde eine "Screening-PCR“ verwendet (Einsele et al., 1997), deren Primer an häufig im Pilzgenom vorkommende Gene, sogenannte "18S-Multicopy-Gene“, binden. Somit ist die Amplifikation der DNA zwar pilzspezifisch, aber nicht speziesspezifisch und alle drei untersuchten Pilzarten können gut detektiert werden. 
Primersequenz (Einsele et al., 1997):

\section{P1 5'-ATTGGAGGGCAAGTCTGGTG-3' \\ P2 5'-CCGATCCCTAGTCGGCATAG-3'}

Die Länge des generierten DNA-Fragments beträgt in Abhängigkeit der Pilzspezies 482-503 bp. Für das Protokoll B wurden die Primer HPLC-gereinigt verwendet; für Protokoll A wurden sie entsalzt eingesetzt.

\section{Primerdesign des Protokolls C}

Bei dem Protokoll C (Jaeger et al., 2000) handelt es sich um eine Nested-PCR, d.h. eine in zwei aufeinander folgenden PCRs verlaufende Amplifikation der DNA. Während der ersten PCR wird mit Hilfe panfungaler Primer die DNA aller Pilzspezies vermehrt („Screening-PCR“; Länge des DNA-Fragments 728 - 744 bp). In der zweiten PCR werden dann speziesspezifische Primer eingesetzt. Hier kamen auf Grund der Vorgabe des Protokolls nur Primer für $C$. albicans (Länge des DNA-Fragments 402 bp) und A. fumigatus (Länge des DNA-Fragments 520 bp) zum Einsatz. Die Proben für $S$. cerevisiae sollten als zusätzliche Negativkontrollen dienen.

Primersequenz (Jaeger et al., 2000):

Panfungale Primer

Pffor 5'-AGGGATGTATTTATTAGATAAAAAATCAA-3'

Pfrev2 5'-CGCAGTAGTTAGTCTTCAGTAAATC-3

C.albicans - spezifische Primer

Cafor2 5'-GGGAGGTAGTGACAATAAATAAC-3'

Carev3 5'-CGTCCCTATTAATCATTACGAT-3' 

A. fumigatus - spezifische Primer
Asfufor
5'-CCAATGCCCTTCGGGGCTCCT-3'
Asfurev
5'-CCTGGTTCCCCCCACAG-3'

\subsubsection{PCR-Protokolle (A-C)}

Protokoll A "Standard“ (Einsele et al., 1997)

PCR-Ansatz (1 x) für konventionellen Thermocycler

Reagenzien

$[\mu l]$

$10 \times$ Reaktions-Puffer

5

$\mathrm{MgCl}_{2}(25 \mathrm{mM})$

14

Taq-Polymerase (1 U)

0,2

dNTP-Mix (25 mM je Nukleotid)

0,4

Wasser; PCR-Grade 18,3

P1-Primer (100 pmol)

P2-Primer (100 pmol)

PCR-Programm Thermocycler T3

Temperatur $\left[{ }^{\circ} \mathrm{C}\right]$

Zeit [sek]

95
95
62
72

Heizdeckeltemperatur $105^{\circ} \mathrm{C}$

Dauer: ca. 3 Std. 
Alle Proben eines Laufs (serielle Verdünnungen der drei Spezies; Bakterien-, Aufarbeitungs- und PCR-Negativkontolle; Positivkontrolle) wurden parallel pipettiert.

Nach Erstellung eines „Mastermixes“ wurde jeder aliquotierte PCR-Ansatz mit je $10 \mu \mathrm{l}$ (d.h. 10\%) aufgearbeiteter DNA vermischt und mit einem konventionellen Thermocycler untersucht (s. 2.1.2.; Modell T3 Biometra/ Göttingen). Nach Abschluss der Amplifikation erfolgte die Detektion der PCR-Produkte mittels Gelelektrophorese (s. 2.2.7.).

Protokoll B „Real-Time-PCR“ (modifiziert nach Löffler et al., 2000b)

PCR-Ansatz (1 x) für Light-Cycler®1.5

$\begin{array}{ll}\text { Reagenzien } & {[\mu \mathrm{l}]}\end{array}$

$\begin{array}{ll}\mathrm{MgCl}_{2}(3 \mathrm{mmol}) & 12\end{array}$

Master-SYBR-Green (inkl. Taq-Polymerase) 2

Wasser; PCR-Grade $\quad 3,5$

$\begin{array}{ll}\text { P1-Primer (12,5 pmol) } & 0,25\end{array}$

$\begin{array}{ll}\text { P2-Primer (12,5 pmol) } & 0,25\end{array}$

PCR Programm Light-Cycler $® 1.5$

Temperatur $\left[{ }^{\circ} \mathrm{C}\right]$

Zeit [sek]

$\begin{array}{ll}95 & 600 \\ 95 & 1 \\ 62 & 15 \\ 42 & 25 \\ & \infty\end{array}$

Dauer: ca. $50 \mathrm{~min}$ 
Nach Erstellung eines „Mastermixes“ wurden die aliquotierten und in die Glaskapillaren überführten $1 \times$ PCR-Ansätze mit jeweils $2 \mu \mathrm{l}$ (d.h. 2\%) aufgearbeiteter DNA vermischt, 30 sek bei 1500 x g zentrifugiert und schließlich in den Light-Cyclerß1.5 eingesetzt.

Die amplifizierten DNA-Fragmente wurden grafisch dargestellt und das Ergebnis ausgedruckt. Anhand der differierenden Schmelzkurven können die verschiedenen Spezies zugeordnet werden (s. 3.2.3.). Zusätzlich wurden die Proben nach erfolgreichem Durchlaufen des Programms in E-cups abzentrifugiert (1500 x g / 30 sek) und das Ergebnis der PCR-Analysen in der FlachbettGelelektrophorese (s. 2.2.7.) bestätigt.

Protokoll C „Nested-PCR“ (Jaeger et al., 2000)

PCR-Ansatz (1x) für Nested-PCR im konventionellen Thermocycler 1. Ansatz mit panfungalen Primern

Reagenzien $[\mu l]$

10 x PCR-Reaktions-Puffer

5

$\mathrm{MgCl}_{2}(25 \mathrm{mM})$

Taq-DNA-Polymerase (1 U)

0,4

dNTP Mix (25 mM je Nukleotid)

0,4

Wasser; PCR-Grade

31,6

Pffor-Primer

0,2

Pfrev-Primer

0,2 
PCR-Programm Thermocycler T3

Temperatur $\left[{ }^{\circ} \mathrm{C}\right]$

Zeit [sek]

95
95
58

Heizdeckeltemperatur $105^{\circ} \mathrm{C}$

Dauer: ca. 1 1/2 Std.

Nach Erstellung eines "Mastermixes“ wurde jeder aliquotierte 1 x PCR-Ansatz mit je $10 \mu \mathrm{l}$ (d.h. 10\%) aufgearbeiteter DNA vermischt und mit einem konventionellen Thermocycler untersucht (s. 2.1.2.; Modell T3 Biometra/ Göttingen). Nach Abschluss der Amplifikation erfolgte die Ergebnisdarstellung mittels Gelelektrophorese (s. 2.2.7.).

PCR-Ansatz (1x) für Nested-PCR im konventionellen Thermocycler 2. Ansatz mit $C$. albicans-spezifischen Primern

\begin{tabular}{lc} 
Reagenzien & {$[\mu \mathrm{l}]$} \\
\hline $10 \times$ PCR-Reaktions-Puffer & 5 \\
$\mathrm{MgCl}_{2}(25 \mathrm{mM})$ & 2 \\
Taq-DNA-Polymerase (1 U) & 0,2 \\
dNTP Mix (25 mM je Nukleotid) & 0,4 \\
Wasser; PCR-Grade & 40,5 \\
Cafor2-Primer & 0,34 \\
Carev3-Primer & 0,36
\end{tabular}


PCR-Ansatz (1x) für Nested-PCR im konventionellen Thermocycler

2. Ansatz mit A. fumigatus-spezifischen Primern

Reagenzien

$[\mu l]$

$10 \times$ PCR-Reaktions-Puffer

5

$\mathrm{MgCl}_{2}(25 \mathrm{mM})$

2

Taq-DNA-Polymerase (1 U)

0,4

dNTP Mix (25 mM je Nukleotid)

0,4

Wasser; PCR-Grade

40,35

Asfufor-Primer

0,38

Asfurev-Primer

0,47

PCR-Programm Thermocycler T3

Temperatur $\left[{ }^{\circ} \mathrm{C}\right]$

Zeit [sek]

\begin{tabular}{l}
\hline 35 \\
95 \\
66
\end{tabular}

Heizdeckeltemperatur $105^{\circ} \mathrm{C}$

Dauer: ca. 2 Std.

Nach Erstellung eines „Mastermixes“ wurde jeder 1 x PCR-Ansatz mit je $1 \mu \mathrm{l}$ erfolgreich amplifizierter DNA der ersten „panfungalen“-PCR-Untersuchung gemischt. Die Untersuchung erfolgte mit einem konventionellen Thermocycler (s. 2.1.2.; Modell T3 Biometra/ Göttingen). Hierbei war das PCR-Programm bei allen verwendeten speziesspezifischen Primern identisch. Nach Abschluss der Amplifikation erfolgte die Ergebnisdarstellung mittels Flachbett-Gelelektrophorese (s. 2.2.7.). 


\subsubsection{Agarose-Gelelektrophorese}

Zur Darstellung der amplifizierten DNA wurde das Verfahren der AgaroseGelelektrophorese verwendet. Hierbei wird die DNA innerhalb eines elektrischen Feldes ihrer Größe nach aufgetrennt und der eingelagerte Farbstoff $\mathrm{EtBr}$ mit UVLicht sichtbar gemacht. Dies ist möglich, da das zum Gel zugegebene Ethidiumbromid (EtBr/ SL: 10mg / ml; EK $1 \mu \mathrm{g} / \mathrm{ml}$ ) in der DNA interkaliert und bei UV-Exposition zur Emission von Fluoreszenzen angeregt wird.

Um die Molekulargewichte der DNA-Produkte bestimmen zu können, wurde stets ein 100bp-Marker als Größenstandart mitgeführt.

\section{1,5\%iges (bzw. 1\%iges) Agarose-Gel:}

$60 \mathrm{ml} 1 \times$ TAE-Puffer wurden mit 0,9 g (bzw. 0,6 g) Agarose vermischt und 2 min in der Mikrowelle aufgekocht. Nach Abkühlung auf ca. $50^{\circ} \mathrm{C}$ wurden $6 \mu \mathrm{l} \mathrm{EtBr}(10$ $\mathrm{mg} / \mathrm{ml}$ ) hinzugefügt. Die nun fertige Lösung wurde in eine, mit einem 16erGelkamm beschickte, Gelkammer geben. Nach ca. 30 min Aushärtephase wurden je $10 \mu$ der amplifizierten DNA mit $2 \mu$ Ladepuffer (6 x "Loading-dye“) versetzt und in die Geltaschen eingebracht. In 1 x TAE-Trennpuffer wurden die Proben ca. 30 min bei $150 \mathrm{~V}$ aufgetrennt und das Gel abschließend unter UV-Licht fotografiert.

\subsubsection{Hybridisierung nach „Southern-Blot"-Verfahren}

Für eine spätere genaue Speziesidentifikation mit paralleler Sensitivitätssteigerung wurde das „Southern-Blot"-Verfahren (modifiziert nach Sambrook et al., 1997) angewandt.

Hierbei wird die aufgetrennte DNA auf eine Nitrocellulose-Membran übertragen und fixiert. Daraufhin wird mit einer speziesspezifischen, Digoxigenin-markierten Sonde hybridisiert und diese mittels Antidigoxigenin-Antikörper (kombiniert mit Peroxidase) detektiert. Durch das ECL®-System (Verwendung laut Herstellerangaben; Gleichung s. Figur 1) können die Banden visuell auf doppelseitigem Film dargestellt werden.

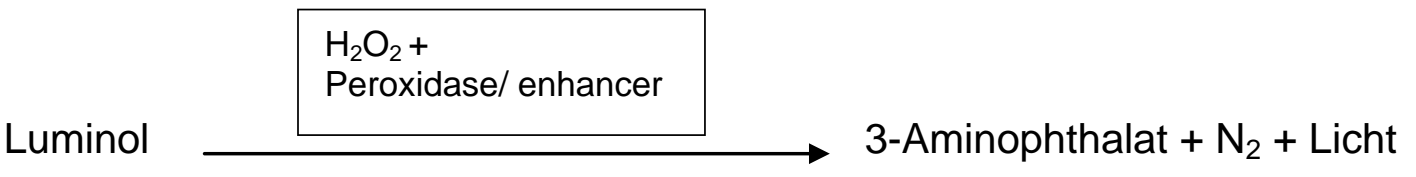

Figur 1: Gleichung ECL $®-S y s t e m$ 


\subsubsection{Sonden}

Die Sondensequenzen, die Hybridisierungstemperatur und die hochstringente Waschtemperatur wurden der Publikation von Einsele et al. (1997) entnommen. Der theoretische Schmelzwert $\left(\mathrm{T}_{\mathrm{m}}\right)$ lag für die $C$. albicans -spezifische Sonde $\mathrm{C}_{\mathrm{Dig}}$ bei $83,2^{\circ} \mathrm{C}$ und für die $A$. fumigatus - spezifische Sonde $A_{D i g}$ bei $85,5^{\circ} \mathrm{C}$.

Da theoretisch Hybridisierungstemperaturen von bis zu $5-10^{\circ} \mathrm{C}$ unter dem $\mathrm{T}_{\mathrm{m}}$ Wert möglich sind, wären für $\mathrm{C}_{\mathrm{DIG}}$ Temperaturen bis zu $73 \mathrm{bzw} .78^{\circ} \mathrm{C}$ denkbar; für $A_{D I G}$ Temperaturen bis zu 75,5 bzw. $80,5^{\circ} \mathrm{C}$.

Berechnungsformel (Sambrook et al., 1997):

$T_{m}=81,5+16,6\left(\log _{10}\left[\mathrm{Na}^{+}\right]\right)+0,41$ (Fraktion $\left.\mathrm{G}^{\prime} s+C^{\prime} s\right)-(600 / \mathrm{N})$

( $N=$ Kettenlänge; $G=$ Guanin; $C=C y$ tosin)

Sonden:

C DIG 5'-TCTGGGTAGCCATTTATGGCGAACCAGGAC-3'

ADIG 5'-TGGGGAACCTCATGGCCTTCACTGGCTGTG-3'

\section{Protokoll:}

1.) Die DNA-Proben wurden in einem $1,5 \%$ igen Agarosegel aufgetrennt und fotografiert (s. 2.2.7.). Anschließend wurden die beiden Gele auf je 4,5 × 9 cm zugeschnitten, um die DNA auf eine Membran übertragen zu können.

2.) Denaturierung mit $0,25 \mathrm{M} \mathrm{HCl} / 10 \mathrm{~min}$

3.) Hydrolyse der DNA und Zerlegung in Einzelstränge mit Hydrolyselösung $2 \times 20 \mathrm{~min}$

4.) Neutralisation in Neutralisationslösung ( $2 \times 20 \mathrm{~min}$; s. 2.1.7.)

5.) Aufbau der Blotting-Aparatur:

Glaswanne mit Transferpuffer (20x SSC) füllen

- $\quad$ Glasplatte quer einlegen; 2 Lagen WHATMANN 3mm Papier so auflegen, dass sie in den Puffer reichen

- Gel mit der Oberseite nach unten auf das Papier auflegen und die Seiten mit Parafilm oder Haushaltsfolie abdecken 
Nitrozellulosemembran zuerst in $\mathrm{H}_{2} \mathrm{O}$ und dann in 2x SSC kurz wässern; daraufhin luftblasenfrei auf das Gel legen 2 Lagen WHATMANN-Papier (in 2x SSC getränkt) auflegen Zellstoff (ca. $20 \mathrm{~cm}$ Dicke) darüber legen und mit Glasplatte und Gewicht beschweren

- $\quad$ Blotzeit $=>12$ Std.; in der Regel über Nacht

6.) Nach dem Blot die Nitrozellulosemembran in 6x SSC waschen

7.) Lufttrocknung der Membran über $30 \mathrm{~min}$; danach Festbacken der DNA im Vakuumofen bei $80^{\circ} \mathrm{C} / 1 \mathrm{Std}$. (alternativ: zeitsparende UV-Quervernetzung der DNA im "Cross-linker")

8.) Prähybridisierung bei $42^{\circ} \mathrm{C} / 2 \mathrm{Std}$. in Prähybridisierungslösung (s. 2.1.7.)

9.) Hybridisierung mit speziesspezifischer Sonde $(\approx 1 \mathrm{pmol} / \mathrm{ml}$ Sondenkonzentration) für max. $3 \mathrm{Std}$. in Prähybridisierungslösung (s. 2.1.7.)

10.) Waschen mit $6 x$ SSC $+0,5 \%$ SDS

a.) Niedrigstringent: $2 \times 15 \mathrm{~min}$ bei $37^{\circ} \mathrm{C}$

b.) Hochstringent: $1 \times 7 \mathrm{~min}$ bei $77^{\circ} \mathrm{C}$

11.) Äquibrilierung der Membran in $\mathrm{PBS} p H$ H,5 bei RT / 1 min

12.) Abblocken des Hintergrundes mit Blockpuffer (s. 2.1.7.) bei RT / 40 min

13.) $10 \mathrm{ml}$ Blockpuffer mit $10 \mu \mathrm{l}$ Anti-Digoxigenin-Antikörper (kombiniert mit Peroxidase (POD); Fab Fragments, $150 \mathrm{mU} / \mathrm{ml}$ ) mischen. Inkubation der Membran bei RT / 1,5 Std.

14.) Waschen mit $1 \times$ PBS $+0,1 \%$ Tween $20 / 3 \times 7$ min

15.) Ansetzten der ECL-Reagenzien 1 und 2 im Verhältnis 1:1 (laut Herstellerangaben; Gesamtvolumen $16 \mu \mathrm{l})$; mindestens $0,125 \mathrm{ml} / \mathrm{cm}^{2}$ Membran

16.) Inkubation der Membran bei RT / 1 min

17.) Einlegen der Membran in eine Klarsichthülle und Überführung in eine Filmkassette

18.) Belichtung des Films (2, 5 und 10 min Intervall; je nach Signalstärke ist die optimale Belichtungszeit differierend ) und Entwicklung

Dauer: ca. 16 Std. zzgl. ca. 12 Std. Blotzeit über Nacht. 


\subsubsection{Kontaminationsprophylaxe/ Kontaminationsquellen}

Zur Kontaminationsprophylaxe wurden die Forderungen von Kwok und Higuchi (1989) angewandt.

DNA-Präparation und PCR-Ansatz fanden in örtlich getrennten Räumen statt. Intermittierende Tisch- und Handschuhhygiene war obligat. Alle Reaktionsgefäße oder Pufferbehältnisse wurden (so weit nicht schon steril angeliefert) autoklaviert verwendet. Um "carry-over"-Kontaminationen von E-cup zu E-cup zu vermeiden wurde, so weit möglich, nur die aktuell zu bearbeitende Probe eröffnet. Es wurden ausschließlich sterile Pipettenspitzen mit Filter verwendet, die so gelagert und gehandhabt wurden, dass eine aerogene Kontamination durch Pilzsporen minimiert wurde.

Als Kontaminationsquellen sind dennoch nicht auszuschließen:

-aerogene Pilzsporen

-Rest-DNA in Pufferlösungen (s. 4.1.)

-PCR Inhibitoren in Pufferlösungen (s. 4.1. \& 4.2.).

\subsubsection{Standardisierung}

Aus Gründen der Standardisierung wurde sowohl die Auszählung als auch die Protokolldurchführung jeweils von der selben Person durchgeführt. Die Hauptversuche (s. 2.2.4. Protokoll III. - VI.; s. 2.2.5. Protokoll VI.b.; s. 2.2.6.2. Protokolle A-C) wurden jeweils mindestens dreimalig unter gleichen Bedingungen durchgeführt. 


\section{Ergebnisse}

\subsection{Vergleich der DNA-Präparationsprotokolle inkl. Protokoll I. und II.}

Um einen direkten Sensitivitätsvergleich der Präparationsprotokolle I. - VI. (s. 2.2.4.) erstellen zu können, wurde das PCR-Protokoll A zur Amplifikation verwendet und somit als „Standard“ definiert (s. 2.2.6.2.).

Bei Beginn der Arbeit wurde in Vorversuchen die generelle Nachweisgrenze der Präparationsprotokolle für $C$. albicans ermittelt.

Hierbei zeigte sich, dass bei Präparationsprotokoll I. (s. 2.2.4.) unter den gegebenen Laborbedingungen bei Konzentrationen von $\leq 9 \times 10^{3}$ Zellen keine Signale mehr detektiert werden konnten. Dies wurde von der Herstellerfirma mit der Aussage bestätigt, dass die minimale Nachweisgrenze für dieses Aufarbeitungsprotokoll bei $1 \times 10^{7}$ Zellen läge. Daraufhin wurde dieses Protokoll aufgrund seiner ungenügenden Effizienz bei keinen weiteren DNA-Präparationen eingesetzt. Bei Protokoll II. verhielt es sich ähnlich. Hier wurde bei den Verdünnungsstufen mit einer DNA-Menge äquivalent zu $9 \times 10^{7}$ C. albicans - Zellen begonnen. Als Ergebnis waren auch hier keinerlei spezifische Signale sichtbar. Ein weiterer Vorversuch mit allen drei zu untersuchenden Spezies und DNAÄquivalenzen von $9 \times 10^{4}-9 \times 10^{-1}$ Zellen zeigte ebenfalls keine Signale.

Hieraus lässt sich schlussfolgern, dass auch das Protokoll II. nicht effizient genug ist. Auch ist eine Standardisierung (vgl. 2.2.4; Protokoll II; Punkt 9.) wegen variierender Mengen Überstandes schlecht möglich. Aus diesen Gründen wurde Protokoll II. ebenfalls zu keinen weiteren Präparationen herangezogen.

Der Zeitaufwand war bei beiden Protokollen mit ca. 4 Std. verhältnismäßig gering. Die Protokolle III. - VI. zeigten bei den im weiteren Verlauf aufgearbeiteten Verdünnungsstufen von $9 \times 10^{4}-9 \times 10^{0}$ gute Ergebnisse, so dass sie als „Hauptversuche“ definiert und wiederholt verwendet wurden. Die dargestellten Sensitivitätsgrenzen (s. 3.1.6.) konnten dabei mindestens dreimalig wiederholt dargestellt werden. 
3.1.1. Protokoll III. (s. 2.2.4.)

$\rightarrow$ DNA-Extraktion mittels enzymatisch-thermischer Lyse unter Verwendung von Phenol-Chloroform-Isoamylalkohol

Auf Grund der Erkenntnisse der Vorversuche wurde bei der DNA-Aufarbeitung mit Verdünnungsstufen von $9 \times 10^{7}-9 \times 10^{0}$ Zellen für $C$. albicans und $A$. fumigatus gearbeitet; für $S$. cerevisiae kamen $9 \times 10^{6}-9 \times 10^{0}$ Zellen zum Einsatz. In der nachfolgenden PCR wurden dann 10\% DNA-Äquivalenzen eingesetzt (s. 2.2.6.2.). Es zeigte sich, dass durch das parallele Bearbeiten einer großen Probenanzahl, den relativ großen Einzelvolumina und durch den finalen Trocknungsvorgang bei offenen E-cups eine hohe Kontaminationsgefahr gegeben ist. Diese resultiert in oftmals durchgängigen Fehl- bzw. Doppelbanden, sowie verunreinigten Kontrollproben (s. Abb. 2).

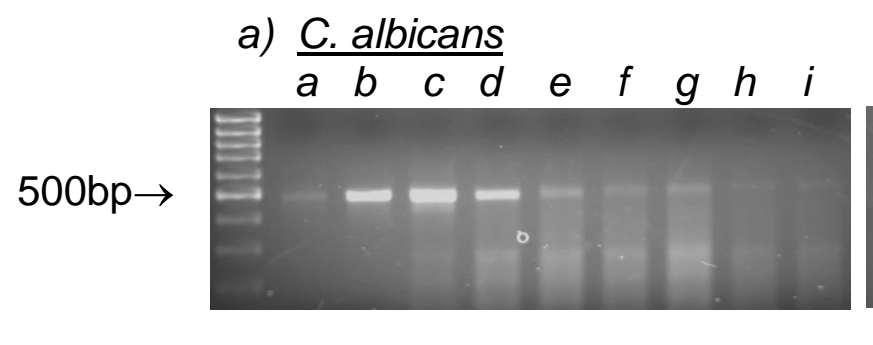

b) S. cerevisiae

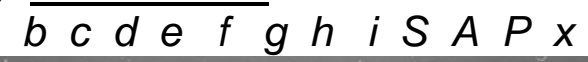

c) A. fumigatus

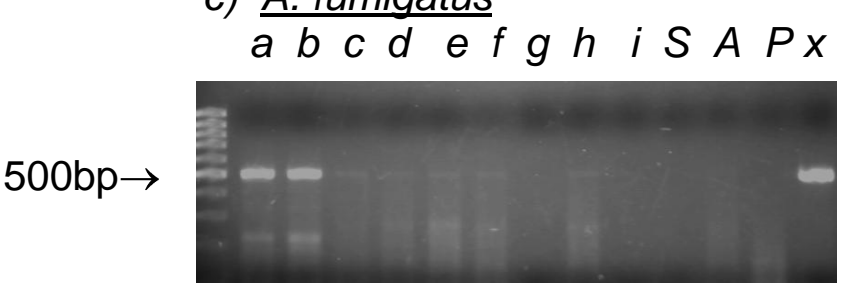

Abbildung 2: Sensitivität des Nachweises der untersuchten Spezies $C$. albicans, A. fumigatus und S. cerevisiae bei Verwendung von Protokoll III. und PCR A

Legende: $\quad$ Buchstaben a $-i$ entsprechen der DNA von $9 \times 10^{7}-9 \times 10^{-1}$ eingesetzten Zellen;

$\mathrm{S}=$ Staphylococcus aureus; $\mathrm{A}=$ Aufarbeitungs-Negativ-Kontrolle;

$\mathrm{P}=$ PCR-Negativ-Kontrolle; $\mathrm{x}=$ C. albicans - Positivkontrolle 
Eine Standardisierung des Protokolls war schlecht möglich, da die Phasentrennung unter Punkt 9. (vgl. Seite 16) anwenderindividuell unterschiedlich ausfällt und somit die überführte DNA-Menge variiert. Somit war eine Reproduzierbarkeit technisch bedingt sehr eingeschränkt.

Auffällig ist die mit $9 \times 10^{6}$ Zellen vergleichsweise geringe Sensitivität bei Verwendung von $A$. fumigatus. Einmalig konnte mit $9 \times 10^{5}$ Zellen hier eine um eine Zehnerpotenz verbesserte Sensitivität nachgewiesen werden. Ebenso ist die schlechte bzw. nicht vorhandene Nachweisbarkeit für hohe DNA-Mengen von $C$. albicans und S. cerevisiae augenscheinlich (s. Bande „a“ für C. albicans \& Bande „b“ für S. cerevisiae).

Durch die erwähnten, häufigen Kontaminationen lässt sich eine Abgrenzung der Sensitivität für die drei bearbeiteten Spezies schwer stellen. Bezug nehmend auf die sich dreimalig wiederholt stark dargestellten DNA-Amplifikate ergeben sich folgende Nachweisgrenzen (s. Abbildung 2 a-c):

\begin{tabular}{|c|c|}
\hline Spezies & Nachweisgrenze (Zellzahl) \\
\hline C. albicans & $9 \times 10^{4}$ \\
\hline A. fumigatus & $9 \times 10^{6}\left(\right.$ einmalig $\left.9 \times 10^{5}\right)$ \\
\hline S. cerevisiae & $9 \times 10^{3}$ \\
\hline
\end{tabular}

Tabelle 1: Nachweisgrenzen von Protokoll III. und PCR A für die eingesetzten Pilzspezies

Die Aufarbeitungsdauer ist mit ca. $4 \mathrm{~h}$ sehr kurz und in den Arbeitsalltag gut integrierbar. 


\subsubsection{Protokoll IV. (s. 2.2.4.)}

$\rightarrow$ thermische Ruptur im Kombination mit Qiagen-Präparation mittels Qiamp®DNA Mini-Kit

Bei relativ guten Nachweisgrenzen für $A$. fumigatus und $S$. cerevisiae können mit diesem Protokoll standardisierte Ergebnisse innerhalb eines Arbeitstages erhalten werden. Lediglich die Nachweisgrenze von C. albicans ist im Vergleich zu den folgenden Protokollen als ungenügend zu bewerten (s. Abb. 3).

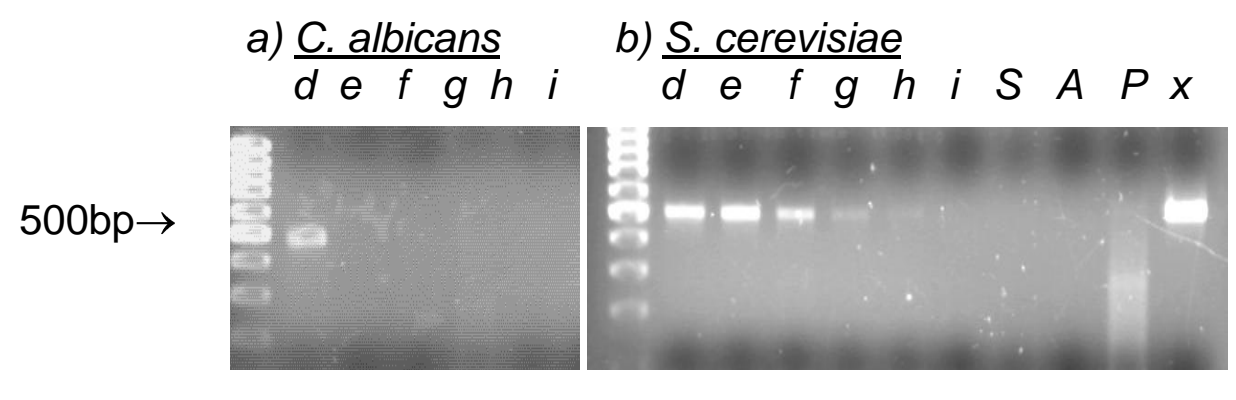
c) $\underline{\text { A. fumigatus }}$
$a b c d e f g h$ i $S A P x$

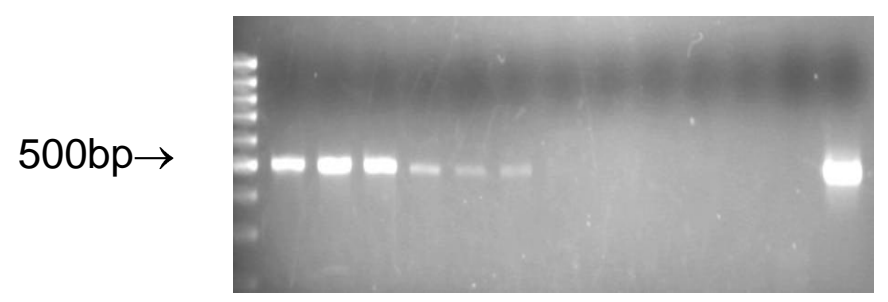

Abbildung 3: $\quad$ Sensitivität des Nachweises der untersuchten Spezies $C$. albicans, A. fumigatus und S. cerevisiae bei Verwendung von Protokoll IV. und PCR A

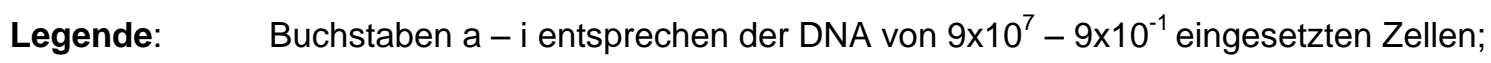

$\mathrm{S}=$ Staphylococcus aureus; $\mathrm{A}=$ Aufarbeitungs-Negativ-Kontrolle;

$\mathrm{P}=$ PCR-Negativ-Kontrolle; $\mathrm{x}=\mathrm{C}$. albicans - Positivkontrolle 
Somit ergeben sich folgende Nachweisgrenzen (s. Abb. 3 a-c):

\begin{tabular}{|c|c|}
\hline Spezies & Nachweisgrenze (Zellzahl) \\
\hline C. albicans & $9 \times 10^{4}$ \\
\hline A. fumigatus & $9 \times 10^{3}\left(\right.$ einmalig $\left.9 \times 10^{2}\right)$ \\
\hline S. cerevisiae & $9 \times 10^{1}$ \\
\hline
\end{tabular}

Tabelle 2: $\quad$ Nachweisgrenzen von Protokoll IV. und PCR A für die eingesetzten Pilzspezies

Die Nachweisgrenze von A. fumigatus ist mit minimal $9 \times 10^{2}$ Zellen schon deutlich niedriger als die von Protokoll III. (s. 3.1.1.). Eine Sensitivitätssteigerung des Nachweises von $C$. albicans ist nicht zu verzeichnen.

Die Aufarbeitungsdauer liegt mit ca. $5 \mathrm{~h}$ nur unwesentlich über der von Protokoll III. und ist somit ebenfalls anwenderfreundlich.

\subsubsection{Protokoll V. (s. 2.2.4.)}

$\rightarrow$ enzymatische Lyse im Kombination mit Qiagen-Präparation mittels Qiamp®DNA Mini-Kit

Dieses, auf zusätzlicher enzymatischer Lyse der Zellwände beruhende Protokoll stellt sich als gut standardisierbar dar, wenngleich eine lange Bearbeitungsdauer mit häufigen Inkubationspausen einkalkuliert werden muss.

Auffällig ist die im Vergleich relativ schlechte Nachweisgrenze für $A$. fumigatus bei gleichzeitig guter Sensitivität für den Nachweis von C. albicans (s. Abb. 4). 

a) C. albicans def $g h$
A. fumigatus
$d e f g h i$
b) $\underline{\text { S. cerevisiae }}$ d e f g h i S A P
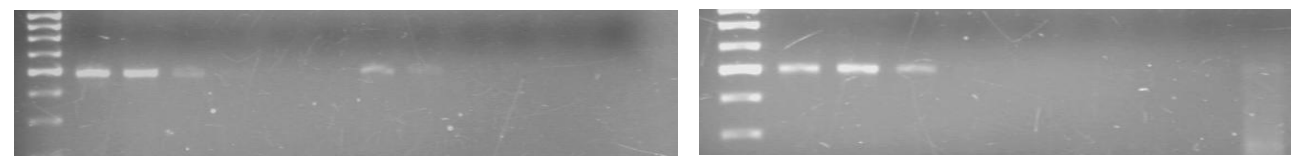

$500 \mathrm{bp} \rightarrow$

Abbildung 4: Sensitivität des Nachweises der untersuchten Spezies C. albicans, A. fumigatus und S. cerevisiae bei Verwendung von Protokoll V. und PCR A

Legende: $\quad$ Buchstaben $d-i$ entsprechen der DNA von $9 \times 10^{4}-9 \times 10^{-1}$ eingesetzten Zellen;

$\mathrm{S}=$ Staphylococcus aureus; $\mathrm{A}$ = Aufarbeitungs-Negativ-Kontrolle;

$\mathrm{P}=\mathrm{PCR}-$ Negativ-Kontrolle

Somit ergeben sich folgende Ergebnisse (s. Abb. 4 a\&b):

\begin{tabular}{|c|c|}
\hline Spezies & $\frac{\text { Nachweisgrenze (Zellzahl) }}{\left.9 \times 10^{2} \text { (einmalig } 9 \times 10^{1}\right)}$ \\
\hline C. albicans & $9 \times 10^{4}$ \\
\hline A. fumigatus & $9 \times 10^{2}$ (einmalig $\left.9 \times 10^{1}\right)$ \\
\hline S. cerevisiae & \\
\hline
\end{tabular}

Tabelle 3: $\quad$ Nachweisgrenzen von Protokoll V. und PCR A für die eingesetzten Pilzspezies

Die Bearbeitungsdauer beträgt mit ca. 6-7 h zwar nahezu einen Arbeitstag; trotzdem ist dieses Protokoll durch häufige Inkubationsphasen gut in den Laboralltag integrierbar. 
3.1.4. Protokoll VI. (s. 2.2.4.)

$\rightarrow$ Kombination aus enzymatischer Lyse und thermischer Ruptur mit nachfolgender Qiagen-Präparation mittels Qiamp®DNA Mini-Kit

Die enzymatische Lyse des Protokolls V. durch Verwendung von Zymolyase scheint weniger effektiv die filamentöse Zellwandstruktur der Spezies $A$. fumigatus aufzubrechen. Der alleinige thermische Rupturvorgang mit Temperaturgradienten von bis zu $286^{\circ} \mathrm{C}$ in kürzester Zeit mit Anwendung von Proteinase $\mathrm{K}$ in Protokoll IV. kann scheinbar die Zellwand von C. albicans nur unzureichend schädigen.

Aus diesen Erkenntnissen der bisher durchgeführten Protokolle entstand ein optimiertes, eigenes Protokoll zur Freisetzung und Reinigung fungaler DNA (Lugert et al., 2006).

Ziel war es, ein Protokoll zu erstellen, das die DNA der beiden untersuchten und medizinisch wichtigen Pilzspezies möglichst effizient isoliert.

Hierzu wurden Elemente aus vorherigen Protokollen miteinander kombiniert. Das Resultat ist eine enzymatische Lyse mittels Zymolyase und Proteinase $\mathrm{K}$ in Kombination mit thermischer Ruptur und abschließend standardisierter DNAAufreinigung durch das Qiamp®DNA-Mini-Kit.

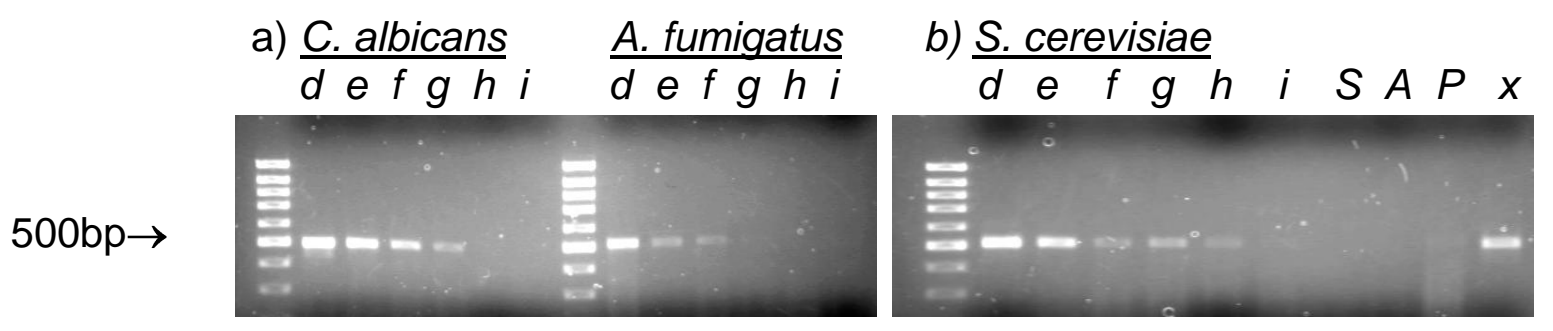

Abbildung 5: Sensitivität des Nachweises der untersuchten Spezies C. albicans, A. fumigatus und S. cerevisiae bei Verwendung von Protokoll VI. und PCR A

Legende: $\quad$ Buchstaben $d-i$ entsprechen der DNA von $9 \times 10^{4}-9 \times 10^{-1}$ eingesetzten Zellen; $\mathrm{S}=$ Staphylococcus aureus; $\mathrm{A}=$ Aufarbeitungs-Negativ-Kontrolle;

$\mathrm{P}=\mathrm{PCR}-$ Negativ-Kontrolle; $\mathrm{x}=\mathrm{C}$. albicans - Positivkontrolle 
Somit ergeben sich folgende Ergebnisse (s. Abb. 5 a\&b):

\begin{tabular}{|c|c|}
\hline Spezies & Nachweisgrenze (Zellzahl) \\
\hline C. albicans & $9 \times 10^{1}$ \\
\hline A. fumigatus & $9 \times 10^{2}$ \\
\hline S. cerevisiae & $9 \times 10^{1}$ (einmalig $9 \times 10^{0}$ ) \\
\hline
\end{tabular}

Tabelle 4: $\quad$ Nachweisgrenzen von Protokoll VI. und PCR A für die eingesetzten Pilzspezies

Wie in Abbildung 5 ersichtlich, konnte mit dieser Aufarbeitungsmethode die höchste Sensitivität des Nachweises der bearbeiteten Spezies erzielt werden. Es ergab sich somit ein für alle untersuchten Spezies universell einsetzbares, reproduzierbares Aufarbeitungsmanagement.

Die Kontaminationswahrscheinlichkeit durch Gefäßwechsel oder offenes Pipettieren ist ähnlich der aus Protokoll V. und somit akzeptabel.

Bezüglich der Aufarbeitungsdauer ist das Protokoll mit ca. $8 \mathrm{~h}$ Bearbeitungsdauer zwar eindeutig das längste der verglichenen DNA-Extraktionsmethoden. Am Ende erzielt es jedoch bei beiden untersuchten, humanpathogenen Spezies die höchste Sensitivität. Somit ist Protokoll VI. den anderen verglichenen Optionen als Screeningmethode deutlich überlegen.

3.1.5. Protokoll VI.b. (s. 2.2.5.)

$\rightarrow$ hypotone Erythrozytenlyse in Kombination mit enzymatischer Lyse und thermischer Ruptur mit nachfolgender Qiagen-Präparation mittels Qiamp®DNA Mini-Kit

Mit dem sensitivsten Protokoll VI. (s. 2.2.4.) wurden die artifiziell infizierten Blutproben einer gesunden Spenderin untersucht. Hierzu wurden die seriellen Pilzsuspensionen mit sterilem EDTA-Blut versetzt und untersucht. Am Anfang fand eine hypotone Erythrozytenlyse unter Verwendung von RCLB (Löffler et al., 1997) statt. Als Ergebnis (vgl. Abb. 6) zeigte sich eine um den Faktor 10 verringerte Sensitivität des Nachweises beider humanpathogener Spezies im Vergleich zur Verwendung von PBS-Puffer-Suspensionen (s. 3.1.6). 


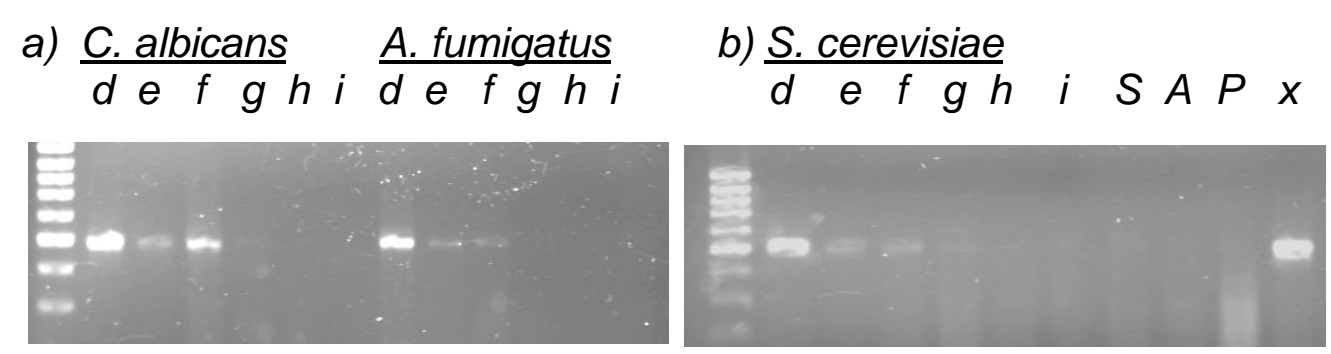

Abbildung 6: Sensitivität des Nachweises der untersuchten Spezies C. albicans, A. fumigatus und S. cerevisiae bei Verwendung von EDTA-Blut als Medium und Protokoll VI.b. und PCR A

Legende: $\quad$ Buchstaben $d-i$ entsprechen der DNA von $9 \times 10^{4}-9 \times 10^{-1}$ eingesetzten Zellen;

$\mathrm{S}=$ Staphylococcus aureus; $\mathrm{A}=$ Aufarbeitungs-Negativ-Kontrolle;

$\mathrm{P}=\mathrm{PCR}-$ Negativ-Kontrolle; $\mathrm{x}=\mathrm{C}$. albicans - Positivkontrolle

Somit ergeben sich folgende Ergebnisse (s. Abb. 5 a\&b und 6 a\&b):

\begin{tabular}{|c|c|c|}
\hline \multirow[t]{2}{*}{ Spezies } & \multicolumn{2}{|c|}{ Nachweisgrenze (Zellzahl) } \\
\hline & Pilzsuspensionen + PCR A & EDTA-Blut-Proben + PCR A \\
\hline C. albicans & $9 \times 10^{1}$ & $9 \times 10^{2}$ (einmalig $9 \times 10^{1}$ ) \\
\hline A. fumigatus & $9 \times 10^{2}$ & $9 \times 10^{3}$ (einmalig $9 \times 10^{2}$ ) \\
\hline S. cerevisiae & $9 \times 10^{1}$ & $9 \times 10^{2}$ \\
\hline
\end{tabular}

Tabelle 5: $\quad$ Nachweisgrenzen von Protokoll VI.b. und PCR A für die eingesetzten Pilzspezies

Der Zeitaufwand durch die zusätzliche Erythrozytenlyse hat eine auf ca. 8,5 h verlängerte Aufarbeitungszeit zur Folge. Somit ist die Integration des kompletten Aufarbeitungsprotokolls in den Arbeitstag schwierig. 


\subsection{6. Übersicht der Aufarbeitungsprotokolle}

\begin{tabular}{|c|c|c|c|c|c|c|}
\hline \multirow[t]{2}{*}{ Protokoll } & \multirow[t]{2}{*}{ Aufarbeitungsart } & \multirow[t]{2}{*}{ Dauer } & \multicolumn{3}{|c|}{$\frac{\text { Nachweisgrenzen der }}{\text { Spezies }}$} & \multirow[t]{2}{*}{ Anmerkungen } \\
\hline & & & $\begin{array}{c}C . \\
\text { albicans }\end{array}$ & $\begin{array}{c}A . \\
\text { fumigatus }\end{array}$ & $\begin{array}{c}S . \\
\text { cerevisiae }\end{array}$ & \\
\hline $\mathrm{I}$. & mechanisch & $4 \mathrm{~h}$ & k.A. & k.A. & k.A. & nicht verwertbar \\
\hline II. & mechanisch & $4 \mathrm{~h}$ & k.A. & k.A. & k.A. & nicht verwertbar \\
\hline III. & $\begin{array}{l}\text { thermisch/ } \\
\text { enzymatisch }\end{array}$ & $4 \mathrm{~h}$ & $9 \times 10^{4}$ & $9 \times 10^{6}$ & $9 \times 10^{3}$ & schlechte Standardisierung \\
\hline IV. & $\begin{array}{l}\text { thermisch/ } \\
\text { enzymatisch }\end{array}$ & $5 \mathrm{~h}$ & $9 \times 10^{4}$ & $9 \times 10^{3}$ & $9 \times 10^{1}$ & $\begin{array}{c}\text { unzureichende Sensitivität } \\
\text { des Nachweises von } C \text {. } \\
\text { albicans }\end{array}$ \\
\hline V. & enzymatisch & $6-7 \mathrm{~h}$ & $9 \times 10^{2}$ & $9 \times 10^{4}$ & $9 \times 10^{2}$ & $\begin{array}{c}\text { hoher Zeitbedarf; } \\
\text { unzureichende Sensitivität } \\
\text { des Nachweises von } A \text {. } \\
\text { fumigatus }\end{array}$ \\
\hline VI. & $\begin{array}{l}\text { thermisch/ } \\
\text { enzymatisch }\end{array}$ & $8 \mathrm{~h}$ & $9 \times 10^{1}$ & $9 \times 10^{2}$ & $9 \times 10^{1}$ & $\begin{array}{l}\text { höchster Zeitbedarf; höchste } \\
\text { Sensitivität des Nachweises } \\
\text { der untersuchten Spezies }\end{array}$ \\
\hline VI.b. & $\begin{array}{l}\text { hypotone Lyse/ } \\
\text { thermisch/ } \\
\text { enzymatisch }\end{array}$ & $8,5 \mathrm{~h}$ & $9 \times 10^{2}$ & $9 \times 10^{3}$ & $9 \times 10^{2}$ & $\begin{array}{l}\text { unzureichende Sensitivität } \\
\text { des Nachweises von EDTA- } \\
\text { Blut-Proben im Vergleich zu } \\
\text { reinen Pilzsuspensionen }\end{array}$ \\
\hline
\end{tabular}

Tabelle 6: Übersicht der Aufarbeitungsprotokolle (s. 2.2.4 \& 2.2.5.) unter Verwendung von Standard-PCR A (s. 2.2.6.2.); k.A.= keine Angabe; Nachweisgrenze in Zellzahl

\subsection{Vergleich der PCR-Amplifikationsprotokolle}

Wie schon unter 3.1. erwähnt, fungierte das PCR-Protokoll A als StandardAmplifikationsmethode, mit welcher der Vergleich der Aufarbeitungsprotokolle III. VI.b. durchgeführt wurde (s. 3.1.1. - 3.1.5.). Als Alternativmethoden wurden sowohl eine Nested-PCR-Technik (s. 3.2.4.), als auch eine zeitoptimierte RealTime-PCR-Methode (s. 3.2.3.) untersucht, die mittels Schmelzkurvenanalyse eine Spezieszuordnung ermöglichen kann. 


\subsection{1. $\quad$ PCR - Protokoll A / Standard (s. 2.2.6.2.)}

Hierzu wurde, wie zuvor bereits erwähnt, ein konventioneller Thermocycler (T3; Biometra Göttingen) mit programmiertem, 34-fachen Heizzyklus verwendet (s. 2.2.6.2.). Das Primerdesign wurde einer Publikation von Einsele et al. (1997) entnommen (s. 2.2.6.1.). In Vorversuchen ergab sich hierbei kein Detektionsunterschied zwischen $1 \mu$ und $10 \mu$ l verwendeter DNA-Suspension, so dass stets mit $10 \mu \mathrm{l}$ gearbeitet wurde.

Die Handhabung dieses Protokolls erwies sich als sehr anwenderfreundlich. Auch hielten sich Logistik- und Zeitaufwand in Grenzen.

Die Nachweisgrenze für die Detektion der eingesetzten Pilzspezies betrug bei mindestens drei unabhängigen PCR-Analysen (s. 2.2.10.) für $C$. albicans und für S. cerevisiae $9 \times 10^{1}$. Bei $A$. fumigatus ergab sich eine Sensitivität von $9 \times 10^{2}$.

\subsubsection{Southern - Blot (s. 2.2.8.)}

$\rightarrow$ nach Durchführung von Protokoll VI. (vgl. 2.2.4.) und PCR A (vgl. 2.2.6.2.)

Zur Verbesserung der Nachweisfähigkeit von fungaler DNA mit gleichzeitiger Möglichkeit der Speziesidentifizierung wurde ein "Southern-Blot" nach DNAAufarbeitung mittels Protokoll VI. (s. 2.2.4.) und Amplifikation durch PCR A (s. 2.2.6.2.) exemplarisch durchgeführt (s. 2.2.8.). Die zu untersuchenden Spezies wurden mindestens dreimal getestet. Da für $S$. cerevisiae keine passende Sonde zur Verfügung stand und der Pilz ohnehin ohne pathologische Relevanz ist, wurde hierbei nur $C$. albicans und $A$. fumigatus eingesetzt. Es zeigte sich für $A$. fumigatus eine um den Faktor 10 verbesserte Nachweisbarkeit nach Hybridisierung gegenüber der alleinigen Gelelektrophorese. Für $C$. albicans bot der Hybridisierungsschritt hier jedoch noch keine durchweg signifikante Sensitivitätssteigerung. Da jedoch in der Gelelektrophorese schwach dargestellte DNA-Banden nach Hybridisierung sehr deutlich sichtbar waren, ist von einer Sensitivitätssteigerung auszugehen (s. Abb. 7).

Die Untersuchungsdauer beträgt ca. $28 \mathrm{~h}$ (inkl. ca. $12 \mathrm{~h}$ Blot-Zeit). 

a) $\underline{\text { C. albicans }}$
A. fumigatus
defghi
defghi

$500 \mathrm{bp} \rightarrow$

Gelelektrophorese nach Verwendung von Protokoll VI. mit PCR A

b) $\frac{\text { C. albicans }}{d e f g h i} \frac{\text { A. fumigatus }}{d e f g h i}$

$500 \mathrm{bp} \rightarrow$

Hybridisierung mit Candida-spezifischer Sonde $\mathrm{C}_{\text {Dig }}$; Belichtungszeit 2 Minuten.

c) $\underline{\text { C. albicans }} \quad \underline{\text { A. fumigatus }}$

$\overline{d e f g h i} \overline{d e f g h} i$

$500 \mathrm{bp} \rightarrow$

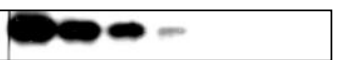

Hybridisierung mit Aspergillus-spezifischer Sonde $\mathrm{A}_{\text {Dig }}$; Belichtungszeit 2 Minuten.

Abbildung 7: Sensitivität des Nachweises der untersuchten Spezies $C$. albicans und $A$. fumigatus bei Verwendung von Protokoll VI. und PCR A (a) mit anschließender speziesspezifischer Hybridisierung (b) und (c)

Legende: $\quad$ Buchstaben $d-i$ entsprechen der DNA von $9 \times 10^{4}-9 \times 10^{-1}$ eingesetzten Zellen

Somit ergeben sich folgende Ergebnisse (s. Abb. 7 a-c):

\begin{tabular}{|c|c|c|}
\hline Spezies & \multicolumn{2}{|c|}{ Nachweisgrenze (Genome) } \\
\hline & $\begin{array}{c}\text { nach alleiniger } \\
\text { Gelelektrophorese (a) }\end{array}$ & $\begin{array}{c}\text { nach zusätzlicher } \\
\text { Hybridisierung (b) \& (c) }\end{array}$ \\
\hline C. albicans & $9 \times 10^{1}$ & $9 \times 10^{1}$ \\
\hline A. fumigatus & $9 \times 10^{2}$ & $9 \times 10^{1}$ \\
\hline S. cerevisiae & $9 \times 10^{1}$ & k.A. \\
\hline
\end{tabular}

Tabelle 7: $\quad$ Nachweisgrenzen von Protokoll VI. und PCR A (a) für die untersuchten Pilzspezies mit anschließender speziesspezifischer Hybridisierung (b) \& (c); k.A. = keine Angabe 


\subsection{3. $\quad$ PCR - Protokoll B / Real-Time-PCR (s. 2.2.6.2.)}

Zur Kontrolle der Real-Time-Amplifikationsmethode wurde parallel mit gleicher DNA die Standard-PCR A (s. 2.2.6.2., Protokoll A) durchgeführt. Hierbei zeigten sich stets Amplifikate für alle untersuchten Spezies, so dass von einer korrekten Aufarbeitung der DNA ausgegangen werden konnte. Nachfolgend durchgeführte Gelelektrophoresen mit durch die Real-Time-PCR amplifizierter DNA bestätigten das graphische Ergebnis.

Im Zuge der weiteren Real-Time-PCR-Analysen konnten alle drei standardmäßig untersuchten Pilz-Spezies ( $C$. albicans; $A$. fumigatus; $S$. cerevisiae) wiederholt unter Verwendung von gleicher DNA-Menge amplifiziert werden (s. Tabelle 8). Hierbei wurde erneut die Verbesserung der Sensitivität durch das Aufarbeitungsprotokoll VI. bestätigt (s. Tabelle 8).

\begin{tabular}{|c|c|c|c|}
\hline Protokoll & \multicolumn{3}{|c|}{ Nachweisgrenze (Genome) } \\
\hline & C. albicans & A. fumigatus & S. cerevisiae \\
\hline IV. & $1,8 \times 10^{4}$ & $1,8 \times 10^{3}$ & $1,8 \times 10^{1}$ \\
\hline V. & $1,8 \times 10^{2}$ & $1,8 \times 10^{4}$ & $1,8 \times 10^{2}$ \\
\hline VI. & $1,8 \times 10^{1}$ & $1,8 \times 10^{2}$ & $1,8 \times 10^{1}$ \\
\hline
\end{tabular}

Tabelle 8: Ergebnisse der Real-Time-PCR-Amplifikationen nach DNA-Aufarbeitung durch Protokolle IV.-VI.

Zur Visualisierung der Speziesidentifikation mittels RT-PCR unter Verwendung des sequenzunspezifischen Fluoreszenzfarbstoffes SYBR-Green wurde eine exemplarische Schmelzkurvenanalyse (s. 2.2.6.) mit der DNA-Menge von $2 \times 10^{4}$ Genome unterschiedlicher humanpathogener Pilze erstellt, die deutlich die speziesspezifisch divergenten Schmelzkurven zeigt (s. Abbildung 8). 


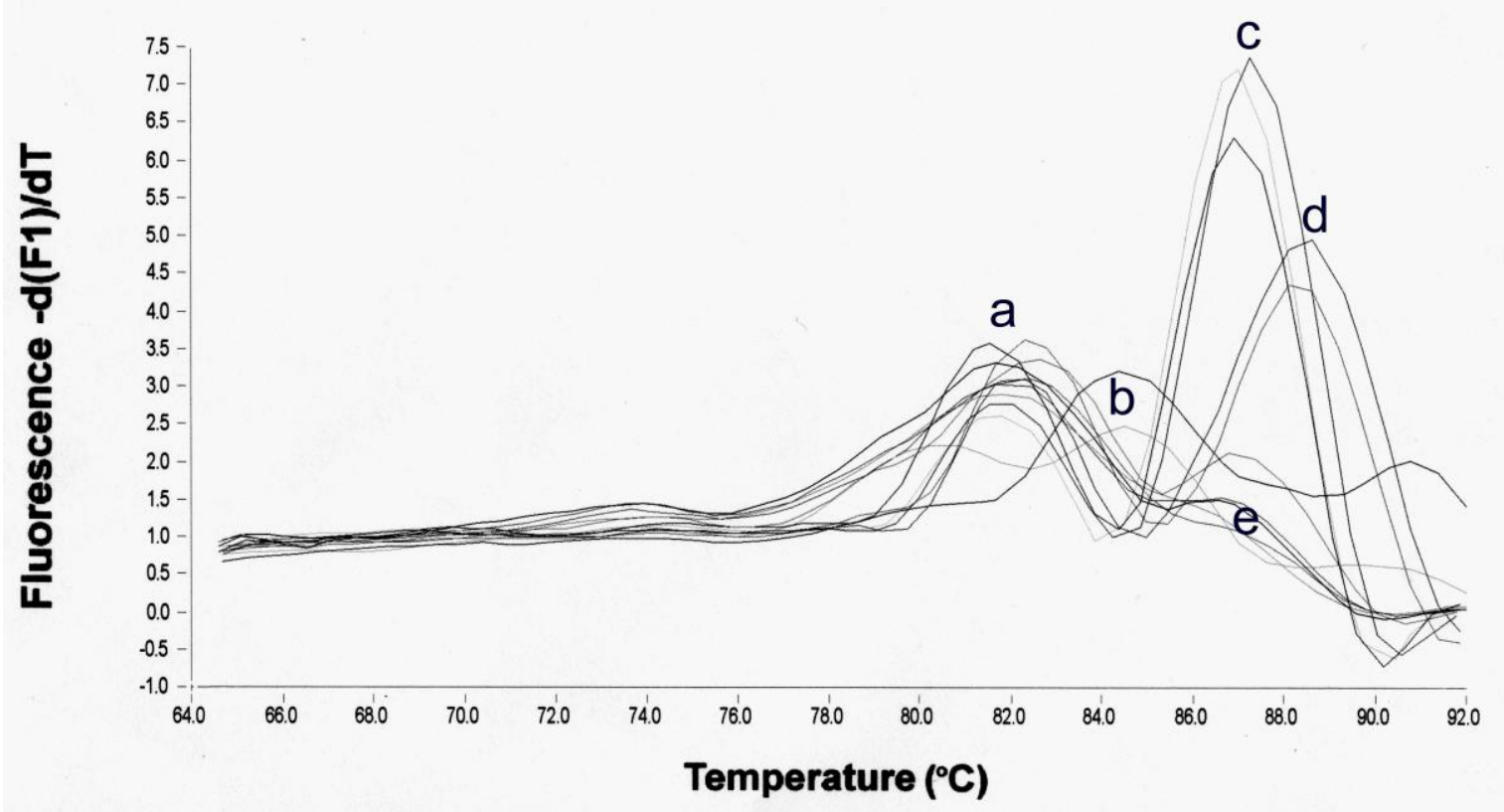

Abbildung 8: Schmelzkurve der Spezies C. albicans, C. tropicalis und S. cerevisiae („C"), $A$. fumigatus und A. flavus („b“), C. glabrata („d“) und der Negativkontrollen („e“) unter Verwendung von Aufarbeitung VI (s. 2.2.4.). Der Peak „a“ stellt unspezifische Primerdimere dar.

An Hand der noch zu ermittelnden definitiven Schmelzwerte (,TM-Werte“) der unterschiedlichen Spezies könnte somit in Zukunft eine eindeutige Speziesidentifikation während der PCR-Untersuchung möglich sein. Weitere Referenzuntersuchungen sind diesbezüglich nötig.

\subsection{4. $\quad$ PCR - Protokoll C / Nested-PCR (s. 2.2.6.2.)}

Die Untersuchungen mittels Nested-PCR (s. 2.2.6.2., Protokoll C) ergaben bei erhöhtem Zeitaufwand trotz mehrfacher Wiederholungen nur unbefriedigende Ergebnisse. Der erste PCR-Lauf unter Verwendung panfungaler Primer zeigte zwar noch identische Ergebnisse wie die des Standardprotokolls A (s. 2.2.6.2., Protokoll A) (s. Abb. 9 a/aa). Im zweiten Teil der Untersuchung ergaben sich jedoch trotz stringenter räumlicher Trennung der Arbeitsschritte unter Verwendung sowohl der Candida-spezifischen, als auch der Aspergillus-spezifischen Primer durchgehend Kontaminationsprobleme, wie exemplarisch in Abbildung 9 b/bb \& 9 $\mathrm{c} / \mathrm{cc}$ ersichtlich. Hierbei kam es bei Verwendung der beiden speziesspezifischen Primer bei allen untersuchten Spezies nahezu durchgehend zu positiven bzw. 
falsch positiven Ergebnissen. Weiterhin führte der zweite, „sensitivitätssteigernde“ Amplifikationszyklus dazu, dass auch die verwendeten Negativkontrollen falsch positive Ergebnisse erbrachten.

\section{PCR-Zyklus}
a) $\frac{\text { C. albicans }}{d e f g h} i \frac{\text { A. fumigatus }}{d e f g h}$ i
aa) $\underline{\text { S. cerevisiae }}$ $\overline{d e f g} h$ i $S A P x$

$700 \mathrm{bp} \rightarrow$
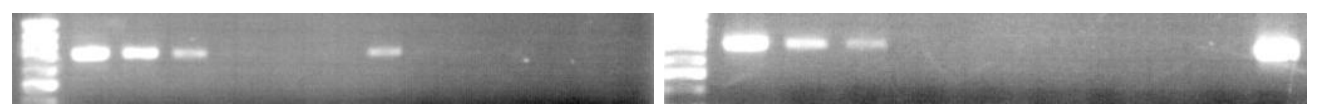

Protokoll V.; PCR C; 1. PCR-Zyklus

2. PCR-Zyklus
b) $\underline{\text { C. albicans }}$
A. fumigatus
bb) S. cerevisiae $\overline{d e f g h} i \overline{d e f g h} i$ $d e f g h$ i $S A P x$

$400 \mathrm{bp} \rightarrow$
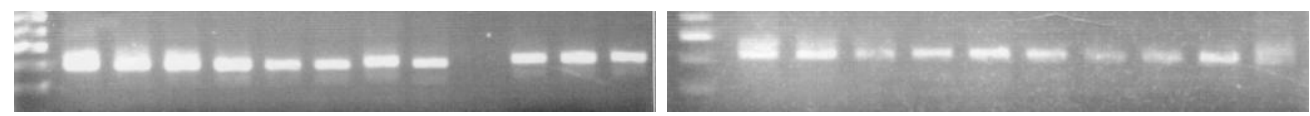

Protokoll V.; PCR C; 2. PCR-Zyklus

Candida-spezifische Primer (Cafor2 \& Carev3)
c) C. albicans
$\frac{\text { A. fumigatus }}{d e f g h}$
cc) S. cerevisiae $d e f g h$ $d e f g h$ i $S A P x$

$400 \mathrm{bp} \rightarrow$
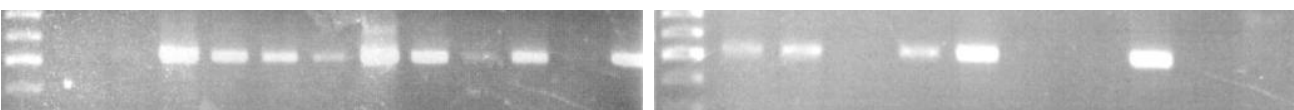

Protokoll V.; PCR C; 2. PCR-Zyklus

Aspergillus-spezifische Primer (Asfufor \& Asfurev)

Abbildung 9: Sensitivität des Nachweises der drei untersuchten Spezies C. albicans, $A$. fumigatus und S. cerevisiae bei Verwendung von Protokoll V. und PCR C

Legende: $\quad$ Buchstaben $d-i$ entsprechen der DNA von $9 \times 10^{4}-9 \times 10^{-1}$ eingesetzten Zellen; $\mathrm{S}=$ Staphylococcus aureus; $\mathrm{A}=$ Aufarbeitungskontrolle/ negativ; $\mathrm{P}=\mathrm{PCR}-$ Kontrolle/negativ; $x=C$. albicans-Positivkontrolle 
Dies lässt den Schluss zu, dass die Nested-PCR bei $50 \%$ höherem Zeitaufwand gegenüber der Standard-PCR A eine sehr hohe Kontaminationsanfälligkeit bietet und daher nicht als standardisierbare "Screening"-PCR praktikabel ist. Auf weitere Nested-PCR-Untersuchungen wurde somit verzichtet.

\subsection{5. Übersicht der Amplifikationsprotokolle}

\begin{tabular}{|c|c|c|c|}
\hline Protokoll & C. albicans & $\underline{\text { A. fumigatus }}$ & $\underline{\text { S. cerevisiae }}$ \\
\hline $\begin{array}{c}\text { A } \\
\text { (Standard) }\end{array}$ & $9 \times 10^{1}$ & $9 \times 10^{2}$ & $9 \times 10^{1}$ \\
\hline $\begin{array}{c}\text { A } \\
\text { (Standard) } \\
\text { +Southern-blotting }\end{array}$ & $9 \times 10^{1}$ & $9 \times 10^{1}$ & k.A. \\
\hline $\begin{array}{c}\text { B } \\
\text { (RT-PCR) }\end{array}$ & $1,8 \times 10^{1}$ & $1,8 \times 10^{2}$ & $1,8 \times 10^{1}$ \\
\hline $\begin{array}{c}\text { C } \\
\text { (Nested-PCR) } \\
\text { Zyklus 1 }\end{array}$ & $9 \times 10^{1}$ & $9 \times 10^{3}$ & $9 \times 10^{1}$ \\
\hline $\begin{array}{c}\text { C } \\
\text { (Nested-PCR) } \\
\text { Zyklus 2 }\end{array}$ & k.A & k.A. & k.A. \\
\hline
\end{tabular}

Tabelle 10: Übersicht der Amplifikationsprotokolle A - C (s. 2.2.6.2. \& 2.2.8) unter Verwendung des Aufarbeitungsprotokolls VI. (s. 2.2.4.); k.A.= keine Angabe; Nachweisgrenze in Genomen 


\section{Diskussion}

Ziel der vorliegenden Arbeit war der Vergleich unterschiedlicher DNA-Extraktionsund Amplifikationsmethoden zum Nachweis von humanpathogenen Pilzspezies, um dadurch die Diagnostik der oftmals foudroyant verlaufenden Mykosen des meistens immunsupprimierten Patienten zu verbessern (Morrell et al., 2005; Greene et al., 2007).

Es wurden unterschiedliche Aufarbeitungstechniken miteinander verglichen und bewertet:

- mechanische Ruptur

- thermische Ruptur

- enzymatische Lyse.

Da die bisher verwendeten Methoden eine unbefriedigende Sensitivität aufwiesen, wurde mit dieser Arbeit ein Aufarbeitungszyklus entwickelt, der die Vorteile von enzymatischer Lyse und thermischer Ruptur in Kombination mit der standardisierbaren Qiagen-Präparation als DNA-Extraktionsmethode verbindet. Hierdurch wurde ein universelles Screeningverfahren zur Diagnostik unterschiedlicher Pilzspezies für den klinischen Alltag etabliert.

Weiterhin wurden die unterschiedlichen Pilz-Konzentrationen mit sterilem, humanen EDTA-Blut versetzt, um die Möglichkeit der DNA-Detektion aus Vollblut exemplarisch zu untersuchen.

Bei den PCR-Amplifikationstechniken wurde in dieser Arbeit eine „Standard“-PCR sowohl mit einer „Real-Time“-Amplifikationsmethode, als auch mit einer „NestedPCR“-Technik verglichen. Exemplarisch wurde die zusätzliche Anwendung eines „Southern-Blots“ als sensitivitätssteigernder Hybridisierungsschritt untersucht. 


\subsection{Effizienz der DNA - Extraktionen}

Auf der einen Seite ist der relativ geringe Zeitaufwand der angewandten Protokolle I. und II. mit ca. 4 Std. verlockend, jedoch erweisen sich die Ergebnisse allein durch mechanische Ruptur als nicht sensitiv genug. Innerhalb der ersten Versuchsreihen ergab sich bereits eine ungenügende Nachweisgrenze für $C$. albicans, so dass diese Protokolle nicht weiter verwendet wurden. Dies korreliert mit den Herstellerangaben des Fast-Prep®-Cell-Disruptors, die eine Mindest-DNAMenge von $10^{7}$ Zellen für eine erfolgreiche Präparation angeben.

Als Möglichkeit der thermisch-enzymatischen Lyse ergab das Protokoll III. (Löffler et al., 2000a) eine ungenaue Nachweisbarkeit hoher DNA-Mengen für $C$. albicans und S. cerevisiae. Ein Grund hierfür könnte die schlechte Standardisierbarkeit und somit erhöhte Fehlerquelle nach Fällung der DNA mit folgender optischer Phasentrennung vor der Weiterverarbeitung sein. Der finale, parallele Trocknungsvorgang der Pellets in geöffneten E-cups kann ebenfalls, z.B. durch aerogene Sporen bei A.fumigatus-Spezies, zu DNA-Verunreinigungen beitragen. Des Weiteren ist die Geruchsbelastung durch das Phenol-Chloroform auch unter optimalen Belüftungsverhältnissen durch Verwendung einer größeren Menge toxischer Substanzen enorm, so dass von einer erhöhten gesundheitlichen Belastung des Laborpersonals auszugehen ist. Trotzdem ist das Protokoll III. ein kompaktes, rasch durchführbares Aufarbeitungsprotokoll, welches für $C$. albicans

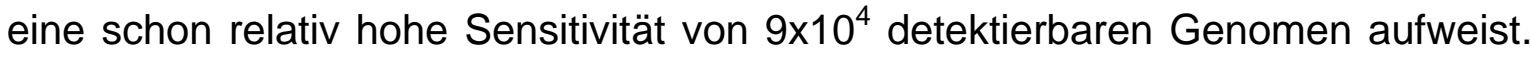
Somit besteht die Möglichkeit, innerhalb eines Labortages suffiziente Ergebnisse zu erzielen.

Das Protokoll IV. (Bialek et al., 2001) zeichnet sich durch seine einfache Handhabung ohne großen materiellen Einsatz, sowie seine relative Zeitersparnis von rund $40 \%$ gegenüber dem zeitlich aufwendigsten Protokoll VI. aus. Proteinase $\mathrm{K}$, eine Serinprotease, wird als Lyseenzym verwendet und dient durch Lösen der Peptidbindungen der Proteine zur Freisetzung von DNA. Dank integriertem Qiagen-DNA-Mini-Kit ist eine gute Standardisierbarkeit der DNA-Extraktion gegeben. Mögliche "carry-over"-Kontaminationen können somit limitiert werden. Leider ergab sich auch hierbei eine relativ schlechte Effizienz des Nachweises von C. albicans, was auf eine zu ineffiziente Wirkweise von Proteinase $\mathrm{K}$ bei Candida- 
Zellen hinweist. Insgesamt stellt das thermisch-enzymatische DNAExtraktionsprotokoll eine schnelle, teilweise jedoch stark kontaminationsbehaftete Methode des Pilznachweises dar. Im Vergleich zu den nachstehenden Protokollen ist die Sensitivität dieses Protokolls schlechter, so dass es für den täglichen klinischen Einsatz nur bedingt empfehlenswert ist.

Bei dem Protokoll V. (Löffler et al., 1997) konnte die bewährte QiagenPräparationsmethode aus dem Protokoll IV. übernommen und mit Zymolyase als weiterem Lyseprotein der Zellwände kombiniert werden.

Zymolyase, aus dem Kulturüberstand von Arthrobacter luteus gewonnen, besitzt als Kombination aus vier Lyse-Enzymen eine hohe Aktivität gegen unterschiedliche Zellwandpolymere von Hefezellwänden. Das Hauptenzym, die beta-1-3-Glucan Laminaripentahydrolase, fragmentiert die Zellwand-Glucane zu Pentameren und die beta-1-3-Glucanase baut die Zellwand durch Hydrolyse zu Glucanen und Glucose ab. Die in geringer Menge vorhandene Protease und Mannase wirken auf die Glycoproteine und Mannane der Hefezellwand und erzeugen so Sphäroblasten, die durch weitere Aufarbeitungsschritte DNA freisetzen können. Hierdurch zeigte sich eine deutliche Verbesserung der Nachweisgrenzen von C. albicans, was die besonders effiziente Wirkweise an den Zellwänden der Hefezellen unterstreicht (Löffler et al., 1997).

Bei $A$. fumigatus hingegen zeigt sich keine signifikante Steigerung der Sensitivität. Gegenteilig wird hier eher eine niedrigere Sensitivität als bei Protokoll IV. gemessen, was auf eine deutlich rigidere Polysaccharid-Wandstruktur der Spezies hindeutet, die sich ohne Thermorupturschritt nur schwer zerstören lässt. Hieraus lässt sich schlussfolgern, dass das Lyseenzym Zymolyase eine unterschiedliche Affinität zu den Zellwandstrukturen der untersuchten Spezies aufweist, gleichzeitig aber in Kombination mit Proteinase K effektive Resultate in der Aufarbeitung von Pilz-DNA erbringen kann.

Die Arbeitsgruppe um Rimek (Rimek et al., 1999) hat bereits Ende der neunziger Jahre gezeigt, dass eine mögliche Kontamination der zu untersuchenden DNA durch mit Saccharomyces-sensu-stricto-Komplex oder Kluyveromyces lodderae verunreinigter Zymloyase hervorgerufen werden kann. Daher sollte die Zymolyase zum Ausschluss etwaiger Kontaminationsmöglichkeiten vor Verwendung auf die Gegenwart von Fremd-DNA mittels PCR getestet werden.

In der hier vorliegenden Arbeit hat sich jedoch nie eine Kontamination durch verunreinigte Zymolyase gezeigt. 
Zusammenfassend lässt sich sagen, dass sich die rein enzymatische Lyse unter Verwendung von Zymolyase und Proteinase K (Protokoll V.) in Kombination mit der gut standardisierbaren Aufarbeitungstechnik des Qiagen-DNA-Mini-Kits für die Spezies $C$. albicans überlegen gegenüber der rein mechanischen (Protokolle I. III.) bzw. der thermisch-enzymatischen (Protokoll IV.) Aufarbeitungsmethoden darstellt. Bei $A$. fumigatus scheint jedoch die thermische Komponente bei der Zellwandruptur eine deutlichere Rolle zu spielen, so dass hier die Kombination aus hohem Temperaturgradienten und enzymatischer Lyse die DNA effektiver freisetzt (Protokoll IV.).

Eine hohe Effizienz der Zellwandlyse bedeutet jedoch auch einen hohen Zeitaufwand, so dass das Protokoll V. mit $6-7$ Std. reiner Aufarbeitungszeit nur erschwert zu Ergebnissen innerhalb eines Labortages führen kann.

Aufgrund der oben genannten Erkenntnisse wurde das kombinierte thermischenzymatische Protokoll VI. unter Einbeziehung von Zymolyase zur optimalen Zellwandruptur aller untersuchten Pilzspezies entwickelt (Lugert et al., 2006). Hier ist allerdings sowohl der zeitliche, als auch der materielle Aufwand im Vergleich zu den anderen Methoden am höchsten, so dass mit Ergebnissen erst nach ca. 8 Std. zu rechnen ist. Ebenfalls ist mit zusätzlichen Arbeitsschritten zur Testung der Zymolyase auf ggf. vorhandene Fremd-DNA zu rechnen. Gleichzeitig stellt dieses Protokoll jedoch die effizienteste DNA-Aufarbeitungsmethode für alle drei untersuchte Pilzspezies dar und ist somit als universelle Screeningmethode geeignet. Durch die sehr gut standardisierbare DNA-Aufreinigung mittels QiagenDNA-Mini-Kit und der nachfolgenden PCR wurden niedrige Nachweisgrenzen für C. albicans ( $9 \times 10^{1}$ Genome), A. fumigatus $\left(9 \times 10^{2}\right.$ Genome) und für $S$. cerevisiae (9x10 Genome) erzielt.

Insgesamt konnte so ein universell einsetzbares Aufarbeitungsschema entwickelt werden, welches mit höchster Effizienz die unterschiedlichen Zellwandstrukturen der untersuchen Spezies aufbricht und unter allen aufgeführten Protokollen die besten Ergebnisse liefert.

Mit Hilfe dieses Protokolls wurde auch die Sensitivität des Pilznachweises in EDTA-Vollblut untersucht. Dabei erfolgte zusätzlich eine vorgeschaltete hypotone Erythrozyten-Lyse, so dass bereits ein Großteil der korpuskulären Anteile des Blutes eliminiert und vor den weiteren Untersuchungsschritten von der verbleibenden Pilz-DNA getrennt wurde. Hierbei ergaben die Versuchsreihen nach PCR eine durchgehend um eine Zehnerpotenz niedrigere Sensitivität im Vergleich 
zum Protokoll VI. und der Verwendung von PBS anstelle von EDTA-Blut. Dies kann an unterschiedlichen, im Vollblut existenten PCR-Inhibitoren liegen. Bekannt ist, dass u.a. sowohl Immunglobulin G (Abu Al-Soud und Rådström, 2000) wie auch Lactoferrin und Hämoglobin die PCR effizient hemmen können und somit als die drei größten PCR-Inhibitoren anzusehen sind (Wilson IG, 1997; Sachse, 2002). EDTA fungiert als Chelatbildner mit $\mathrm{Mg}^{2+}$-Ionen (Rossen et al., 1992) und wirkt somit ebenfalls PCR hemmend. Die Untereinheiten des Hämoglobins, das Häm und Bilirubin, können Eisen-lonen in die PCR-Mixtur einbringen und die Amplifikationseffizienz dadurch stark vermindern (Bruhn und Fölsch, 2008). Ebenso gilt Häm als kompetitiver Inhibitor der Ziel-DNA mit regulatorischer Wirkung auf die DNA-Polymerase (Sachse, 2002). Zur weiteren Etablierung der Methode in der klinischen Diagnostik erscheint es daher sinnvoll, sogenannte Inhibitionskontrollen mitzuführen. Dabei wird ein Aliquot des zu untersuchenden Patientenmaterials artifiziell mit Pilz-DNA kontaminiert und davon dann parallel eine PCR durchgeführt.

\subsection{Vergleich der DNA-Amplifikationsmethoden}

$\mathrm{Zu}$ Anfang wurden alle aufgearbeiteten DNA-Proben nach dem als „Standard“ definierten konventionellen PCR-Protokoll A amplifiziert, um die Sensitivitätsgrenzen der Aufarbeitungsprotokolle miteinander zu vergleichen.

Unter Verwendung der in 2.2.6.1. aufgeführten panfungalen Primer, die zwar pilzspezifisch, nicht aber speziesspezifisch an „18S-Multicopy-Gene“ binden, kann dieses breit angelegte, universelle PCR-Protokoll vorhandene Pilz-DNA effizient amplifizieren. Somit stellt es eine gute Screeningmöglichkeit für die Erregersuche im klinischen Alltag dar. Exemplarisch wurde ebenfalls die für Menschen apathogene Bäckerhefe $S$. cerevisiae mit aufgearbeitet und amplifiziert. Die anzusetzenden 90 Minuten bis zum Erhalt der Ergebnisse nach EthidiumbromidFärbung und Gelelektophorese sind relativ gering.

Entgegen den Ergebnissen von Einsele et al. (1997) wurde jedoch aus Gründen der Zeitoptimierung der finale Hybridisierungsschritt mittels „Southern-Blot“Verfahren nicht permanent, sondern nur exemplarisch unter Verwendung des 
sensitivsten Aufarbeitungsprotokolls VI. durchgeführt. Durch Weglassen der Hybridisierung konnte somit eine Zeitersparnis von $~ 28$ Std. erzielt werden. Jedoch ist ein gleichzeitiger Sensitivitätsverlust von bis zu $10^{1}$ Genomen einzukalkulieren. Die Ergebnisse zeigen dennoch sehr sensitive Nachweisgrenzen für $C$. albicans und $A$. fumigatus von $9 \times 10^{1}$ bzw. $9 \times 10^{2}$ Genomen auch ohne Hybridisierungsschritt.

Nach „Southern-Blotting“ mittels Digoxigenin-markierter Oligonukleotid-Sonden konnte die Nachweisgrenze für $A$. fumigatus nochmals um eine Zehnerpotenz auf $9 \times 10^{1}$ Genome bei gleichzeitiger Spezifizierung der Proben gesenkt werden. Man kann davon ausgehen, dass eine ähnliche Sensitivitätssteigerung durch die abschließende Hybridisierung auch bei $C$. albicans möglich ist, hier jedoch wegen der geringen Anzahl der Untersuchungen noch nicht gelang.

Somit zeigen die in der vorliegenden Arbeit erzielten Ergebnisse eine geringere Sensitivität als die von Einsele et al. (1997) erzielten: Hier konnten nach Hybridisierung ein bzw. zwei Genome für C. albicans bzw. A. fumigatus detektiert werden. Etwaige Sensitivitätsunterschiede könnten sich durch den unterschiedlichen apparativen und labortechnischen Aufbau der Versuchsprotokolle erklären lassen. Sowohl die Taq-Polymerasen als auch die Thermocycler wurden von unterschiedlichen Herstellern verwendet und können somit zu Diskrepanzen der Ergebnisse beitragen.

Zusammenfassend lässt sich sagen, dass das PCR-Protokoll A nach Einsele et al. (1997) ein gut standardisierbares, universell einsetzbares, relativ zeitintensives und wenig kontaminationsbelastetes Screeningprotokoll für Pilz-DNA darstellt. Dennoch muss stringent auf eine örtliche Trennung der Arbeitsschritte bei bestmöglichen Hygienestandards geachtet werden, um Kreuzkontaminationen durch aerogene Pilzsporen oder Rest-DNA in Pufferlösungen zu vermeiden.

Bei der Nested-PCR wird nach einer initialen DNA-Amplifikation mittels panfungaler Primer zum Screening des Patientenmaterials auf vorhandene PilzDNA ein zweiter PCR-Zyklus mit speziesspezifischen Primern im konventionellen Thermocycler durchgeführt (Jaeger et al., 2000). Mit dieser Vorgehensweise soll eine signifikante Sensitivitätssteigerung erreicht und im zweiten Schritt speziesspezifische DNA amplifiziert werden.

Im ersten „Screening“-Zyklus unter Verwendung panfungaler Primer konnte die in PBS verdünnte, aufgearbeitete DNA mit hoher Sensitivität nachgewiesen werden: Für $C$. albicans und $S$. cerevisiae lag die Nachweisgrenze bei $9 \times 10^{1}$ Genomen; bei 
A. fumigatus konnten $9 \times 10^{3}$ Genome detektiert werden. Dies liegt unterhalb der von Riggsby et al. (1982) bzw. Jaeger et al. (2000) erzielten Sensitivitäten, die den Nachweis von 10pg Candida-DNA (entsprechend 270 Genomen) bzw. 100pg Aspergillus-DNA nach panfungaler PCR (entsprechend dem ersten PCR-Zyklus) erzielten.

Der zweite PCR-Zyklus unter Verwendung der speziesspezifischen Primer ergab in unserer Untersuchung im Gegensatz zu den bisher veröffentlichten Daten enttäuschende Ergebnisse. Ein Grund hierfür könnte sein, dass Riggsby et al. (1982) und Jaeger et al. (2000) ausschließlich gereinigte DNA verwendeten.

Anstatt der erwarteten Sensitiviätssteigerung ergaben unsere Untersuchungen nahezu durchgehende, falsch positive Ergebnisse. Auch nach mehrmaliger Wiederholung der Testläufe unter Berücksichtigung bestmöglicher Hygienestandards und stringenter örtlicher Trennung der Arbeitsschritte konnte dieses Phänomen nicht komplett ausgeblendet werden.

Es ist möglich, dass durch die hohe Probenanzahl und mögliche aerogene Sporen die Untersuchungsproben nicht gänzlich steril gehalten werden konnten. Auch ist der deutlich erhöhte materielle und zeitliche Untersuchungsbedarf mit mehr als 200 Minuten bei insgesamt drei herzustellenden PCR-Zyklen wesentlich aufwändiger als der der anderen durchgeführten PCR-Protokolle.

Generell erscheint die Nested-PCR-Technik für eine große Probenanzahl aus den genannten Gründen eher ungeeignet und sollte daher als Screenigmethode nur unter Vorbehalt Verwendung finden.

Um eine zeitliche Optimierung der Ergebnisse zu erzielen, wurde das von Löffler et al. (2000b) publizierte Real-Time-PCR-Protokoll modifiziert verwendet. Hierbei wird der konventionelle Thermocycler durch den Light-Cycler® ersetzt. Die Primer wurden der Publikation von Einsele et al. (1997) entnommen. Das PCRSetting war bei gleichzeitiger Erhöhung der Zyklenanzahl ähnlich.

Anstelle der in der Originalpublikation (Löffler et al., 2000b) verwendeten FRETAnalyse (Fluoreszenz-Resonanz-Energie-Transfer) (Clegg, 1995; Wittwer et al., 1997b), die unter Verwendung von speziesspezifischen Oligonukleotiden eine eindeutige Identifikation der eingesetzten DNA erlaubt hätte, lag das Augenmerk in der vorliegenden Untersuchung primär auf dem Vergleich der Sensitivitätsgrenzen bei Optimierung des zeitlichen Laborablaufs.

Daher wurde hier SYBR-Green zur Detektion der amplifizierten DNA eingesetzt. Somit wird unter Verwendung der panfungalen Primer mit nachfolgender 
Schmelzkurvenanalyse innerhalb eines PCR-Laufs der Nachweis eines breiten Spektrums unterschiedlicher Pilz-DNA ermöglicht. In Zukunft könnte über die Bestimmung der speziesindividuellen DNA-Schmelzwerte (, $T_{M}$-Werte") eine genaue Identifizierung der jeweiligen Pilzart erzielt werden. Dies konnte in dieser Arbeit bereits für unterschiedliche humanpathogene Pilzspezies exemplarisch dargestellt werden.

Mit dem in dieser Arbeit erstellten Untersuchungsaufbau konnte eine Nachweisgrenze von $1,8 \times 10^{1}$ Genome für $C$. albicans und $S$. cerevisiae, sowie $1,8 \times 10^{2}$ Genome für $A$. fumigatus erzielt werden. Somit wird die höhere Sensitivität dieser Amplifikationstechnik gegenüber Standard-PCR deutlich. Würde der zusätzliche Hybridisierungschritt hier ebenfalls eingepflegt werden, könnte eine weitere Sensitivitätssteigerung bei gleichzeitiger Speziesidentifikation durch Verwendung der spezifischen Oligonukleotidsonden erzielt werden. Löffler et al. (2000b) konnten unter Anwendung der FRET-Analyse eine Sensitivität von fünf CFU je Spezies bei gleichzeitiger Spezifikation der untersuchten DNA erreichen.

Mit einem Zeitaufwand von ca. 50 Minuten ist die DNA-Amplifikation bei gleichzeitig erhöhter Zyklenzahl gegenüber der Standard-PCR nahezu halbiert. Nachteilig an dieser Untersuchungstechnik ist ganz offensichtlich das offene, parallele Bestücken der Real-Time-PCR-Röhrchen mit aufgearbeiteter DNA, was eventuell zu Kontaminationen beitragen könnte.

Zusammenfassend ergibt die Real-Time-PCR das beste und zeiteffizienteste Amplifikationsverfahren aller untersuchten PCR-Protokolle bei gleichzeitig sehr guter Sensitivität. 


\section{Zusammenfassung}

Mit der hier vorliegenden Arbeit wurde das Ziel verfolgt, eine möglichst schnelle und effiziente Methode des Nachweises der häufigsten humanpathogenen Pilzspezies zu etablieren.

Die klinisch initial oft inapparent und bei immunsupprimierten Patienten nicht selten letal verlaufenden systemischen Mykosen wie Candidiasis und Aspergillose werden bisher häufig zu spät diagnostiziert. Daher bestand das Ziel dieser Arbeit darin, den Stellenwert der PCR und verschiedener DNA-Aufarbeitungsmethoden zu evaluieren: Hierzu wurden unterschiedliche, bereits bekannte Aufarbeitungstechniken zur Zerstörung der rigiden Zellwand der Pilzzellen mit nachfolgender Reinigung und Amplifikation der DNA miteinander verglichen. Es zeigte sich, dass auf Grund der verschiedenen Zellwandstrukturen von $C$. albicans und $A$. fumigatus unterschiedliche Aufarbeitungsschritte notwendig sind. Die thermisch-enzymatische DNA-Elution war nur für $A$. fumigatus relativ sensibel. Bei der rein enzymatischen Aufarbeitung unter Verwendung von Zymolyase und Proteinase $\mathrm{K}$ konnte $C$. albicans mit einer deutlich höheren Sensitivität als $A$. fumigatus nachgewiesen werden. Um die beiden häufigsten Pilzgattungen Candida und Aspergillus gleichermaßen nachweisen zu können, wurde ein Protokoll entwickelt, das die thermische Ruptur und die Verwendung der Lyseenzyme Proteinase K und Zymolyase kombiniert.

Nach Identifikation bzw. Entwicklung der effizientesten DNA-Aufarbeitungsmethode wurden im zweiten Teil dieser Arbeit unterschiedliche DNA-Amplifikationsmethoden miteinander verglichen. Dabei zeigte sich, dass die Real-Time-PCR-Technik mittels Light-Cycler ${ }^{\circledR}$ unter Verwendung des sequenzunabhängigen Fluoreszenzfarbstoffes SYBR-Green bei niedrigstem Zeitaufwand den sensitivsten Nachweis von $C$. albicans und $A$. fumigatus erbrachte. Die Kombination aus der universell verwendbaren, relativ zeitintensiven DNA-Aufarbeitung mit der zeiteffizienten Real-Time-PCRTechnik ergibt somit einen effektiven Synergismus für den sensitiven Nachweis humanpathogener Pilzspezies. 


\section{Literaturverzeichnis}

Abi-Said D, Anaissie E, Uzun O, Raad I, Pinzcowski H, Vartivarian S (1997): The epidemiology of hematogenous candidiasis caused by different Candida species. Clin Infect Dis 24:1122-1128

Abu Al-Soud W, Rådström P (2000):

Effects of amplification facilitators on diagnostic PCR in the presence of blood, feces and meat. J Clin Microbiol 38(12):4463-70

Andrutis KA, Riggle PJ, Kumamoto CA, Tzipori S (2000):

Intestinal lesions associated with disseminated candidiasis in an experimental animal model. J Clin Microbiol 38:2317-23

Bassetti M, Taramasso L, Nicco E, Molinari MP, Mussap M, Viscoli C (2011): Epidemiology, species distibution, antifungal susceptibility and outcome of nosocomial candidemia in a tertiary care hospital in Italy. PloS One 6(9):e24198

Beck-Sagué C, Jarvis WR (1993):

Secular trends in the epidemiology of nosocomial fungal infections in the United States, 1980-1990. J Infect Dis 167:1247-1251

\section{Berg FT:}

Om torsk hos barn. L.J. Hjerta, Stockholm 1846

Bialek R, Fischer J, Feucht A, Najvar LK, Dietz K, Knobloch J, Graybill JR (2001):

Diagnosis and monitoring of murine histoplasmosis by a nested PCR assay. J Clin Microbiol 39:1506-1509

Birch DE (1996):

Simplified hot start PCR. Nature 381:445-446

Bodey GP, Anaissie EJ, Edwards JE :

Definitions of Candida infections; in: Bodey GP: Candidiasis: Pathogenesis, diagnosis and treatment. Raven Press, New York 1993, 407-08

Bouza E, Munoz P (2008):

Epidemiology of candidemia in intensive care units Int J Antimicrob Agents 32:87-91

Bouza E, Perez-Molina J, Munoz P (1999):

Report of ESGNI01 and ESGNI02 studies. Bloostream infections in Europe Clin Microbiol Infect $\underline{5}: 1-12$

Bruhn HD, Fölsch UR:

Labormedizin. Interaktionen, Methodik und Laborwerte. Pathophysiologie und Klinik. Schattauer Verlag, Stuttgart 2008, 302 
Clegg RM (1995):

Fluorescence resonance energy transfer. Curr Opin Biotechnol $\underline{6}: 103-110$

Denning DW (1996):

Therapeutic outcome in invasive aspergillosis. Clin Infect Dis $\underline{23}: 608-615$

Edmond MB, Wallace SE, McClish DK, Pfaller MA, Jones RN, Wenzel RP (1999) :

Nosocomial bloodstream infections in United States hospitals: a three-year analysis. Clin Infect Dis 29(2):239-44

Einsele H, Hebart H, Roller G, Löffler J, Rothehöfer I, Müller CA, Bowden RA, van Burik J-A, Engelhard D, Kanz L,Schumacher U (1997):

Detection and identification of fungal pathogens in blood by using molecular probes. J Clin Microbiol 35:1353-1360

Erjavec Z, Kluin-Nelemans H, Verweij PE (2009):

Trends in invasive fungal infections, with emphasis in invasive aspergillosis. Clin Microbiol Infect 15:625-633

Fonzi WA, Irwin MY (1993):

Isogenic strain construction and gene mapping in Candida albicans. Genetics 134(3):717-28

Fresenius JBGW:

Beitrag zur Mykologie 3. Heinrich Ludwig Brönner Verlag, Frankfurt am Main 1863, 81-82

Greene RE, Schlamm HT, Oestmann JW (2007):

Imaging findings in acute invasive pulmonary aspergillosis: clinical significance of the halo-sign. Clin Infect Dis 44:373-379

Hachem R, Hanna H, Kontoyiannis D, Jiang Y, Raad I (2008):

The changing epidemiology of invasive candidiasis: Candida glabrata and Candida krusei as the leading causes of candidemia in hematologic malignancy. Cancer 112:2493-2499

Hawksworth DL (2001):

The magnitude of fungal diversity: the 1,5 Million species estimate revisited. Mycol Res 105:1422-1432

Hjortrup A, Rassmussen A, Hansen BA, Høiby N, Heslet L, Moesgaard F, Kirkrgaard P (1997):

Early bacterial and fungal infection in liver transplantation after oral selective bowel decontamination. Transpl Proc $\underline{29}: 3106-10$

Jaeger EEM, Carroll NM, Choudhury S, Dunlop AAS, Towler HMA, Matheson MM, Adamson P, Okhravi N, Lightman S (2000):

Rapid detection and identification of Candida, Aspergillus and Fusarium species in ocular samples using Nested PCR. J Clin Microbiol 38:2902-2908 
Kappe R, Schulze-Berge A, Sonntag HE (1996):

Evaluation of eight antibody tests and one antigen test for the diagnosis of invasive aspergillosis. Mycoses 39(1-2):13-23

Kellogg DE, Rybalkin I, Mukhamedova N, Vlasik T, Siebert PD, Chenchik A (1994):

TaqStart antibody: "hot start" PCR facilitated by a neutralizing antibody directed against Taq DNA polymerase. Biotechniques 16:1134-1137

Kousha M, Tadi R, Soubani AO (2011):

Pulmonary aspergillosis: a clinical review. Eur Respir Rev 20(121):156-74

Kullberg BJ, Oude Lashof AM (2002):

Epidemiology of opportunistic invasive mycoses. Eur J Med Res $\underline{7}: 183-191$

Kriengkauykiat J, Ito Jl, Dadwal SS (2011):

Epidemiology and treatment approaches in management of invasive fungal infections. Clin Epidemiol $\underline{3}: 175-91$

Kwok S, Higuchi R (1989):

Avoiding false positives with PCR. Nature $\underline{339}: 237-8$

Labbe AC, Su SH, Lavardiere M (2007):

High incidence of invasive aspergillosis associated with intestinal graft-versus-host disease following nonmyoablative transplantation.

Biol Blood Marrow Transplant 13:1192-200

Latgé JP (1999):

Aspergillus fumigatus and aspergillosis. Clin Microbiol Rev 12:310-350

Lin S-J, Schranz J, Teutsch SM (2001):

Aspergillosis case-fatality rate: systemic review of the literature.

Clin Infect Dis $\underline{32}: 358-66$

Löffler J, Hebart H, Schumacher U, Reitze H, Einsele H (1997):

Comparison of different methods for extraction of DNA of fungal pathogens from cultures and blood. J Clin Microbiol 35:3311-3312

Löffler J, Hebart H, Brauchle U, Schumacher U, Einsele H (2000a):

Comparison between plasma and whole blood specimens for detection of Aspergillus DNA by PCR. J Clin Microbiol 38:3830-3833

Löffler J, Henke N, Hebart H, Schmidt D, Hagmeyer L, Schumacher U, Einsele H (2000b):

Quantification of fungal DNA by using Fluorescense Resonance Energy Transfer and the Light Cycler system. J Clin Microbiol 38:586-590

Lugert R, Schettler C, Gross U (2006):

Comparison of different protocols for DNA preparation and PCR for the detection of fungal pathogens in vitro. Mycoses 49:298-304 
Markin RS, Stratta RJ, Woods GL (1990):

Infection after liver transplantation. Am J Surg Pathol 14(1):64-78

Marty F, Mylonakis E (2002):

Antifungal use in HIV infection. Expert Opin Pharmacother $\underline{3}: 91-102$

McNeil MM, Nash SL, Hajjeh RA, Phelan MA, Conn LA, Plikaytis BD, Warnock DW (2001):

Trends in mortality due to invasive mycotic diseases in the United States, 19801997. Clin Infect Dis 33:641-647

\section{Medicus FC:}

Pflanzen-physiologische Abhandlungen. Entstehung der Schwämme. Vegetabilische Crystallisation. Von den Ursachen der Saftbewegung im Pflanzenreiche. Band 3. Heinrich Gräff Verlag, Leipzig 1803

Mikulska M, Bassetti M, Ratto S, Viscoli C (2011):

Invasive Candidiasis in Non-Hematological Patients. Mediterr J Hematol Infect Dis 3:e2011007

Morrell M, Fraser VJ, Kollef MH (2005):

Delaying the empiric treatment of candida bloodstream infections until positive blood culture results are obtained: a potential risk factor for hospital mortality Antimicrob Agents Chemother 49:3640-3645

Müller F-MC, Werner KE, Kasai M, Francesconi A, Chanock SJ, Walsh TJ (1998):

Rapid extraction of genomic DNA from medically important yeasts and filamentous fungi by high-speed cell disruption. J Clin Microbiol 36:1625-1629

Mullis K, Faloona F, Scharf S, Saiki R, Horn G, Ehrlich H (1986):

Specific enzymatic amplification of DNA in vitro: the polymerase chain reaction. Cold Spring Harb Symp Quant Biol 51:263-273

Nucci M, Marr KA (2005):

Emerging fungal diseases. Clin Infect Dis $\underline{41}: 521-526$

Patel R, CV Paya (1997):

Infections in solid-organ transplant recipients. J Clin Microbiol Rev 10:86-124

Patterson TF, Kirkpatrick WR, White M (2000):

Invasive aspergillosis. Disease spectrum, treatment practices and outcomes. Medicine $\underline{\text { 79(4):250-260 }}$

Pereira GH, Muller PR, Szeszs MW, Levin AS, Melhem MS (2010):

Five-year evaluation of bloodstream yeast infections in a tertiary hospital: the predominance of non-C. albicans candida species. Med Mycol 48(6):839-42

Pfaller MA, Diekema DJ (2007):

Epidemiology of invasive candidiasis: a persistent public health problem. Clin Microbiol Rev 20:133-163 
Rangel-Frausto MS, Wiblin T, Blumberg HM, Saiman L, Patterson J, Rinaldi M, Pfaller M, Edwards JE Jr., Jarvis W, Dawson J, Wenzel RP (1999):

National epidemiology of mycoses survey (NEMIS): variations in rates of bloodstream infections due to Candida species in seven surgical intensive care units and six neonatal intensive care units. Clin Infect Dis 29:253-258

\section{Rasmussen R:}

Quantification on the Light-Cycler; in: Meuer S, Wittwer C, Nakagawara K: Rapid Cycle Real-Time PCR: Methods and Applications. Springer Verlag, Berlin 2001, 21-34

Reichard U, Büttner S, Eiffert H, Staib F, Rüchel R (1990):

Purification and charakterisation of an extracellular serine proteinase from Aspergillus fumigatus and its detection in tissue. J Med Microbiol 33:243-251

Riggsby WS, Torres-Bauza LJ, Wills JW, Townes TM (1982):

DNA content, kinetic complexity and the ploidy question in Candida albicans. Mol Cell Biol 2:853-862

Rimek D, Garg AP, Haas WH, Kappe R (1999):

Identification of contaminating fungal DNA sequences in zymolyase. $\mathrm{J}$ Clin Microbiol 37:830-1

Rossen L, Nǿrskov P, Holstrǿm K, Rasmussen OF (1992):

Inhibition of PCR by components of food samples, microbial diagnostic assays and DNA-extraction solutions. Int J Food Microbiol 17(1):37-45

Rubin RH (2002):

Overview: pathogenesis of fungal infections in the organ transplant recipient. Transpl Infect Dis $\underline{4}: 12-17$

Ruhnke M, Böhme A, Buchheidt D, Donhuijsen K, Einsele H et al. (2003):

Diagnosis of invasive fungal infections in hematology and oncology. Guidelines of the infectious Diseases Working Party (AGIHO) of the German Society of Hematology and Oncology (DGHO). Ann Hematol $\underline{82: 141-148}$

\section{Sachse K:}

Specificity and performance of diagnostic PCR assays; in: Sachse K \& Frey J: Methods in molecular biology, vol. 216: PCR detection of microbiol pathogens. Humana Press Inc., Totowa/ New Jersey 2002, 30-34

\section{Sambrook J, Fritsch EF, Maniatis T:}

Molecular cloning. A laboratory manual. Bd. 2. Cold Spring Harbor Laboratory Press, New York 1997

Stevens DA, Kan VL, Judson MA (2000):

Practice guidelines for diseases caused by Aspergillus. Clin Infect Dis $\underline{30: 696-709}$

Sundstrom P (1999):

Adhesins in Candida albicans. Curr Opin Microbiol 2(4):353-7 
Upton A, Kirby KA, Carpenter P, Boeckh M, Marr KA (2007):

Invasive aspergillosis following haematopoetic cell transplantation: outcomes and prognostic factors associated with mortality. Clin Infect Dis 44:531-540

Wald A, Leisenring W, van Burik JA, Bowden RA (1997):

Epidemiology of Aspergillus infections in a larger cohort of patients undergoing bone marrow transplantation. J Infect Dis 175(6):1459-1466

Walsh TJ (1998):

Primary cutaneous aspergillosis - an emerging infection among immunocompromised patients. Clin Infect Dis 27(3):453-7

Wanke B, Santos Lazéra M, Nucci M (2000):

Fungal infections in the immuncompromised host. Mem Inst Oswaldo Cruz 95:153-158

Warris A, Voss A, Verweij PE (2001):

Hospital sources of Aspergillus: New routes of transmission? Rev Iberoam Micol 18(4):156-62

Wilson IG (1997):

Inhibition and facilitation of nucleic acid amplification. Appl Environ Microbiol $\underline{63}: 3741-3751$

Wilson LS, Reyes CM, Stolpman M, Speckman J, Allen K, Beney J (2002):

The direct cost and incidence of systemic fungal infections. Value Health $\underline{5}: 26-34$

Winston DJ, C Emmamonilides, RW Busutill (1995):

Infections in liver transplant recipients. Clin Infect Dis 21(5):1077-89

Wisplinghoff $\mathrm{H}$, Bischoff $\mathrm{T}$, Tallent SM, Seifert H, Wenzel RP, Edmond MB (2004):

Nosocomial bloodstream infections in US hospitals: Analysis of 24.179 cases from a prospective nationwide surveillance study. Clin Infect Dis 39:309-317

Wittwer CT, Fillmore GC, Garling DJ (1990):

Minimizing the time required for DNA amplification by efficient transfer to small samples. Anal Biochem 186:328-331

Wittwer CT, Garling DJ (1991):

Rapid cycle DNA amplification: time and temperature optimization. Biotechniques 10:76-83

Wittwer CT, Ririe KM, Andrew RV, David DA, Gundry RA, Balis U (1997a):

The LightCycler: a microvolume multisample fluorimeter with rapid temperature control. Biotechniques 22:176-181

Wittwer CT, Herrmann MG, Moss AA, Rasmussen RP (1997b):

Continuous fluorescence monitoring of rapid cycle DNA amplification. Biotechniques 22:130-131,134-138 


\section{Danksagung}

Zu aller Erst möchte ich ganz herzlich meinem Doktorvater Prof. Dr. med. Uwe Groß für die Übertragung dieses spannenden Disserationsthemas und die Bereitstellung des Laborplatzes danken.

Seine Tür stand zu jeder Zeit prompt und gerne offen für Anregungen und Diskussionen - ohne seine stete Unterstützung beim Fortgang der Arbeit wäre ich sicherlich nie so weit gekommen.

Ganz besonders möchte ich mich an dieser Stelle bei Herrn Dr. phil. nat. Raimond Lugert bedanken. Ohne sein immer offenes Ohr, seinen schier nie enden wollenden Optimismus beim Fortgang der Arbeit und seinem sicherlich übernormalen, konstruktiven Engagement während der prolongierten Abfassung wäre diese Arbeit wahrscheinlich nie zu Stande gekommen.

Herrn Prof. Dr. med. Utz Reichardt und Frau Prof. Dr. M. Borg-von Zepelin möchte ich hier für die freundliche Überlassung der Spezies-Proben danken.

Mein weiterer Dank gilt dem gesamten Team des Mikrobiologischen Instituts der Universität Göttingen. Hierbei war vor allem die freundschaftliche, immer von Unterstützung geprägte Zusammenarbeit mit Frau K. Kunze und Frau M. Targatz ganz besonders bereichernd. Vielen Dank dafür!

"Last but not least" gilt ein besonderer Dank meiner Ehefrau Birgit, die mit ihrem Verständnis, ihrer Anteilnahme und nicht zuletzt ihrer fachlichen Kompetenz bei der Durchsicht dieser Arbeit immer an meiner Seite stand. 


\section{Lebenslauf}

Ich wurde am 13.10.1977 als zweiter Sohn der Lehrerin Margret Schettler und des Physikers Dr. Rolf Schettler in Northeim geboren.

Von 1983 bis 1987 absolvierte ich meine Grundschulzeit in Hattorf am Harz, um anschließend von 1987 bis 1989 die Orientierungsstufe in Wulften zu besuchen.

Ab 1989 bis 1993 absolvierte ich die Unterstufe des Gymnasiums in Herzberg am Harz. Anschließend folgte ein einjähriger Einführungssprachkurs Russisch an der staatlichen Universität Kharkov/ Ukraine, welchen ich erfolgreich abschloss.

Ab 1994 besuchte ich die Oberstufe des Gymnasiums Herzberg und legte dort 1997 die allgemeine Hochschulreife ab.

Von 1997 bis 1998 diente ich während meiner Wehrdienstzeit bei der

Fernmeldeeinheit Frankenberg/ Eder; anschließend folgte ein viermonatiges

Pflegepraktikum in den Kliniken Herzberg und Osterode $\mathrm{GmbH}$.

Im Oktober 1998 schrieb ich mich für das Erststudium für Humanmedizin an der Georg-August-Universität zu Göttingen ein. Nach Durchführung des praktischen Jahres am Diakonie-Krankenhaus Rotenburg/ Wümme mit dem Wahlfach Neurologie schloss ich mein Studium im November 2005 mit dem dritten Staatsexamen erfolgreich ab. Von Anfang Dezember 2005 bis Ende Dezember 2006 war ich als Assistenzarzt der I. Medizinischen Klinik des DiakonieKrankenhauses Rotenburg/ Wümme unter Leitung von Herrn Chefarzt Prof. Dr. med. J. Potratz in den Schwerpunkten Kardiologie/ Onkologie tätig.

Ab Januar 2007 realisierte ich zusammen mit meiner Ehefrau Birgit unser privat organisiertes Entwicklungshilfeprojekt „Spuren-hinterlassen.com“ während unserer zehnmonatigen Westafrikadurchquerung. Hierbei engagierte ich mich vor Ort ehrenamtlich im Schwerpunkt Tropenmedizin im Rahmen einer mehrwöchigen ärztlichen Tätigkeit im G.P.H.A.-Hospital in Takoradi/ Ghana.

Seit März 2008 bin ich als Assistenzarzt der Inneren Medizin bei den Kliniken Herzberg und Osterode $\mathrm{GmbH}$ unter der Leitung der Chefärzte Dres. Thiele und Schmidt (Schwerpunkte Kardiologie und Gastroenterologie) angestellt. Ich habe zwei wunderbare Töchter, Johannah Abiona \& Julia Meara. 